Rev. Hist., N²7, vol. 2, Julio-Diciembre 2020: 143-174

\title{
Mediadores políticos y culturales: los misioneros franciscanos del colegio de Chillán y la expansión fronteriza al sur del imperio español a finales del siglo xviii ${ }^{*}$
}

\author{
Political and cultural go-betweens: the franciscan missionaries of the college of chillan \\ and the border expansion south of the spanish empire at the end of the eighteenth \\ century
}

Cristóbal Vega Arévalo: ORCID: https://orcid.org/0000-0001-9535-4394**

Francis Goicovich: ORCID: https://orcid.org/0000-0002-3507-3002 ${ }^{* * *}$

\section{RESUMEN}

En la primera mitad del siglo XVIII los métodos misionales y seculares se encontraron desprestigiados y desgastados, por lo que reinó la inestabilidad en la frontera mapuche del Imperio español en América. Sin embargo, no fue hasta 1756 cuando se inyectó un verdadero impulso misional renovado con la erección del Colegio de Propaganda Fide de Chillán. En poco tiempo esta institución ganó terreno en la agenda borbónica, y luego del extrañamiento de los jesuitas, se alzaría como un instrumento de primer orden para gestar y mantener las relaciones pacíficas ultra Biobío. Así, este artículo tiene como objetivo mostrar el impacto que tuvo el Colegio seráfico entre 1756 y 1803, mostrándonos un papel que pocas veces se les ha reconocido a los hijos de San Francisco: vislumbrarlos más allá de la interpretación enmarcada en el fracaso misional, por cuanto los esfuerzos desplegados por la Propaganda Fide resultaron esenciales para la política de resguardo territorial y promoción de la paz con los indígenas. Todo en miras de enriquecer el debate en torno al capítulo de la evangelización colonial allende el Biobío.

Palabras claves: Franciscanos, Colegio de Propaganda Fide, Chillán, Frontera Mapuche, Reformas Borbónicas, Evangelización Indígena

\footnotetext{
* Investigación financiada por la Vicerrectoría de Investigación y Desarrollo (VID) de la Universidad de Chile, en el marco de un proyecto concursable del Programa de Apoyo a la Productividad Académica en Cs. Sociales, Humanidades, Artes y Educación (PROA) del año 2018. Deseamos expresar nuestro agradecimiento a David Rex Galindo, colega, amigo y profesor de la Universidad Adolfo Ibáñez, por su generosa revisión del manuscrito. Extendemos el reconocimiento a los evaluadores anónimos, cuyas consideraciones contribuyeron a perfeccionar el escrito.

** Licenciado en Historia, Universidad de Chile. Estudiante del Programa de Magíster en Historia, Universidad de Chile. Email: cristobal.vega@ug.uchile.cl

*** Licenciado en Historia y Licenciado en Antropología con mención en Arqueología, Universidad de Chile. Magíster en Historia con mención en Etnohistoria, Universidad de Chile. Ph.D. in History, University of Texas at Austin. Profesor del Departamento de Ciencias Históricas, Universidad de Chile. Email: fgoicovi@uchile.cl.
} 


\begin{abstract}
In the first half of the 18th-century, missionary and secular methods were discredited and worn out, so instability prevailed on the Mapuche border of the Spanish Empire in America. However, it was not until 1756 when a real renewed missionary impulse was injected with the erection of the College of Propaganda Fide in Chillán. In a short time, this institution gained the attention of the Bourbon agenda, and after the expulsion of the Jesuits, it rose as an important instrument to develop and maintain peaceful relations beyond the Bio Bío river. Thus, this article aims to unveil the Colegio's impact between the 1756 and 1803, showing a role that has rarely been credited to the San Francisco' sons: to see them beyond the interpretation framed in missionary failure, because the works by the Propaganda Fide were essential elements for the policy of territorial protection and promotion of peace with the indigenous. All this in order to enrich the debate on the colonial evangelization issue beyond the Biobío river.
\end{abstract}

Key words: Franciscans, College of Propaganda Fide, Chillan, Mapuche Borderland, Bourbon Reforms, Indigenous Evangelization

Recibido: diciembre 2019

Aceptado: agosto 2019

\title{
Introducción
}

Al clarear el siglo XVIII la convulsión política en España llevó al poder a los Borbones. Esto supuso una renovación en torno a la idea de regencia, administración y comercio, dando paso a la era de la Ilustración en la península. Como refiere David Weber, la España de los primeros conquistadores ya no existía y una fatigada dinastía había dado paso a un periodo lleno de dinamismo, que introdujo la necesidad de un Estado más próspero y unificado ${ }^{1}$. Así, de la mano del racionalismo militante se emprendió una revisión crítica del orden tradicional dando paso a nuevos preceptos políticos, económicos y sociales ${ }^{2}$, y a un renovado tratamiento hacia la población del continente americano, cuya consecuencia directa fue poner en entredicho las concepciones fundadas en la ignorancia e indiferencia acerca de los indios y la naturaleza del Nuevo Mundo ${ }^{3}$.

Fue precisamente dentro de este cambio epistemológico, en el que la espiritualidad barroca cedió su lugar al pragmatismo de la razón ilustrada, que se experimentó una modificación en el trato hacia las misiones de evangelización. A ojos de la nueva administración dieciochesca el lapso de alrededor de un siglo y medio de trabajo misional emprendido por la Compañía de

\footnotetext{
1 Weber, David. 2005. Bárbaros: Spaniards and their savages in the Age of Enlightenment, New Haven, Yale University Press, p. 2.

2 Martínez, Enrique y De Pazzis Pi Corrales, Magdalena (eds.). 2008. Ilustración, ciencia y técnica en el siglo XVIII español, Valencia, PUV, p. 14.

${ }^{3}$ Weber. 2005. Bárbaros, pp. 3-4.
} 
Jesús en la frontera chilena no había arrojado los resultados esperados, por lo que se comenzó a buscar candidatos que garantizasen formas de apostolado más eficientes entre los nativos. Las correrías jesuitas no cabían dentro de la nueva lógica que buscaba un control efectivo y una demarcación territorial clara, yendo más allá de la insustancialidad de lo puramente sacramental. Como escribe Leonardo León, el siglo XVIII comenzó con el objetivo de establecer el estado de derecho para desterrar el desorden y la anarquía a lo largo y ancho del territorio fronterizo. En ese sentido, el imperio de la paz entre españoles y mapuches empezó a ser visto como la pieza fundamental en la construcción de nuevas relaciones fronterizas ${ }^{4}$.

A partir de la última década de la pasada centuria la categoría "frontera", como herramienta de análisis histórico, ha experimentado una serie de transformaciones en su conceptualización fundadora. Esta reconfiguración se asienta, en buena medida, sobre una reevaluación gestada a partir de la convocación interdisciplinar que caracteriza a los métodos y técnicas de investigación de las humanidades y ciencias sociales en la actualidad. La eurocéntrica visión turneriana, que apelaba a la idea de un límite en constante expansión que separaba a dos mundos diversos e irreconciliables, proceso en el que la "civilización" inevitablemente habría de imponerse sobre la "barbarie", ha cedido su lugar a una aproximación que privilegia las interrelaciones económicas, sociales, políticas y culturales que enlazaba a dichos mundos, sin obviar por ello la existencia de momentos de conflicto ${ }^{5}$. No es necesario recurrir a la bibliografía de otras regiones para comprobar que la tradicional concepción de la frontera como frente de conquista en continua progresión es puesta en cuestionamiento por la historia de la frontera del Biobío, la que bien sabemos nació de un repliegue del movimiento colonizador como consecuencia de una serie de alzamientos indígenas, fracasando toda tentativa por reimplantar la dinámica de avance de los primeros años de presencia española en el sur de Chile $^{6}$. Las fronteras son concebidas como espacios sociales dinámicos, en los que se produce un activo intercambio y tránsito multidireccional de bienes y personas, no solo definidas por la confrontación sino también por la mutua dependencia, involucrando intereses y necesidades diversos ${ }^{7}$. Con esta nueva perspectiva se busca garantizar no solo una equilibrada construcción histórico-social de los espacios de interacción cultural, sino también rescatar las relaciones

${ }^{4}$ León, Leonardo. 2001. "Que la dicha herida se la dio de buena sin que interviniese traición alguna...: El ordenamiento del Espacio Fronterizo Mapuche, 1726-1750", en Revista de Historia Social y de las Mentalidades, Vol. 5, № 1, Santiago, p. 130.

${ }^{5}$ Sobre este punto véase el interesante trabajo de Mónica Quijada. 2002. "Repensando la frontera sur argentina: concepto, contenido, continuidades y discontinuidades de una realidad es pacial y étnica (siglos XVIII-XIX)", en Revista de Indias, Vol. LXII, № 224, Madrid, pp. 103-142.

${ }^{6}$ Zavala, José. 2008. Los mapuches del siglo XVIII. Dinámica interétnica y estrategias de resistencia, Santiago, Editorial Universidad Bolivariana, p. 98.

7 Altube, María Inés. 1999. "Mujeres en "tierra adentro'. Las cautivas en las sociedades indígenas de la región pampeana y norpatagónica (siglos XVIII y XIX)", en Villar, Daniel, Di Liscia, María y Caviglia, María Jorgelina (eds.), Historia y género: seis estudios sobre la condición femenina, Buenos Aires, Editorial Biblos, p. 90. 
establecidas entre las sociedades que conviven $y$, al mismo tiempo, compiten por esos espacios ${ }^{8}$, resaltando aspectos como la permeabilidad, la complementariedad y la rivalidad.

En un escenario histórico de estas características, definido por transformaciones y reacomodos, salpicado de necesidades emergentes nacidas de las nuevas circunstancias, se proyectó la tarea del Colegio de Propaganda Fide de Chillán. De origen franciscano, jurídicamente dependiente del Comisario General de Indias, aunque en aspectos canónicos de la Sacra Congregatio de Propaganda Fide, con sede en Roma, el Colegio no era único ni tampoco exclusivo del reino, sino parte de un movimiento global de contrarreforma llevado a cabo por el propio papado, por lo que fue un ente hermano de otros de igual configuración (el Colegio de Chillán estuvo directamente emparentado con el Colegio de Santa Rosa de Ocopa, en Perú) $)^{9}$. A partir de 1622 la Congregación delineó planes para la fundación de colegios con la finalidad de coordinar la actividad misionera en ultramar, haciéndose cargo de la evangelización de los "infieles" en los continentes fuera de Europa, de los "herejes" luteranos o calvinistas en el viejo continente, y también de los ortodoxos en la Europa oriental ${ }^{10}$. En el continente americano recayó en los franciscanos la tarea de reimpulsar el fervor misionero de comienzos de la conquista, buscando la conversión indígena a la vida cristiana en su totalidad ${ }^{11}$. Estaban regidos por la bula Ecclesiae Catolicae de Inocencio XI y se les otorgó su propio reglamento, lo que les dio una existencia independiente de las provincias franciscanas oficiales ${ }^{12}$, recibiendo subvención de la Corona ${ }^{13}$.

En consecuencia, cabe preguntarse ¿qué significó para los reformistas Borbones el impulso misionero del Colegio de Propaganda Fide de Chillán en la frontera? ¿Cuál fue el rol que asignaron a los seráficos en un siglo de ideas ilustradas? Buscando dilucidar estas interrogantes, en el presente artículo estudiamos el trabajo franciscano con los mapuches entre 1756, momento de su fundación, y 1803, año del Parlamento de Negrete, periodo en el que la Corona implementó nuevos métodos de cristianización en la Frontera. Postulamos que el Colegio de

\footnotetext{
${ }^{8}$ Areces, Nidia. 1999. "Regiones y fronteras. Apuntes desde la historia", en Andes Antropología e Historia, № 10, Salta, p. 25.

${ }_{9}^{9}$ Sobre el origen de los Colegios de Propaganda Fide y su establecimiento en el Nuevo Mundo, véase Rex Galindo, David. 2018. To sin no more: Franciscans and conversion in the Hispanic world, 1683-1830, Stanford, Stanford University Press/The Academy of American Franciscan History, pp. 28-45.

10 Pizzorusso, Giovanni. 2016. "The Congregation de Propaganda Fide, the Holy See and the native peoples of North America (17 $17^{\text {th }} 19^{\text {th }}$ centuries)", en Cummings, Kathleen y Sanfilippo, Matteo (eds.), Holy See's archives as sources for American history, Vitterbo, Sette Città, p. 22.

11 Guarda, Gabriel. 2016. La Edad Media en Chile. Historia de la Iglesia: desde la fundación de Santiago a la incorporación de Chiloé, 1541-1826, Santiago, Ediciones UC, p. 191.

12 Iturriaga, Rigoberto. 1992. Reglamento de misiones del Colegio de Chillán, Santiago, Publicaciones del Archivo Franciscano (en adelante PAF), № 21, Santiago,1992.

${ }^{13}$ Leal, Cristián y Quitral, Andrés. 2017. “Evangelización y occidentalización en la frontera sur del Reino de Chile. Los franciscanos del Colegio de Misiones de Chillán, s. XVIII", en Historia y Memoria, № 15, Universidad Pedagógica y Tecnoncógica de Colomnia, p. 143.
} 
Propaganda Fide de Chillán se configuró como una herramienta esencial del Estado Borbón para establecer y mantener, con un ímpetu misional renovado, las relaciones fronterizas, buscando soslayar los peligros de un alzamiento general o una invasión extranjera a través de la intermediación de dos opuestos, mapuches y españoles.

En el presente estudio analizaremos el rol jugado por el Colegio de Propaganda en la frontera sur de Chile y su utilidad frente a las coyunturas que surgieron en la segunda mitad del siglo XVIII. El objetivo es poner en tela de juicio el consenso existente entre ciertos autores que plantean la ineficacia del trabajo misional, a pesar de los esfuerzos desplegados por la Corona y los misioneros ${ }^{14}$, y destacar la labor mediadora de los religiosos en una época borbónica en la que se experimentó un repliegue eclesiástico frente al asalto de los administradores. Así, por ejemplo, Jorge Pinto sostiene que "la historia de los franciscanos en la Araucanía se reduce a un constante y penoso fracaso"15. En su concepto, los seráficos no pudieron escapar a su mentalidad etnocentrista y vocación etnocida, ya que el objetivo irrenunciable de construir el mundo de Dios en la tierra los hizo poco tolerantes a aceptar los usos y costumbres de los indígenas, instándolos, en circunstancias apremiantes, a avalar el empleo de la fuerza para imponer su verdad ${ }^{16}$. Por el contrario, pensamos que no toda la acción del Colegio fue un fracaso, y que además no existió una única vocación ni mentalidad misionera, ya que las investigaciones más recientes han demostrado que hubo misioneros más adaptados que otros, algunos con políticas interétnicas brutales y otros mucho más tolerantes ${ }^{17}$.

La presente investigación se enmarca en una tendencia historiográfica creciente que reivindica la acción de los hijos de San Francisco de Asís en el continente americano, otorgándoles un protagonismo que muchas veces ha sido obnubilado por el trabajo desplegado por la Compañía de Jesús. En el estudio de la situación fronteriza de Chile en el siglo XVIII destacan en el último tiempo las figuras de María Pía Poblete Segú, quien profundiza en la labor educativa asumida en tierras huilliches a través del establecimiento de escuelas para hijos de

\footnotetext{
${ }^{14}$ Foerster, Rolf. 1996. Jesuitas y Mapuches, 1593-1767, Santiago, Editorial Universitaria, p. 17.

15 Pinto, Jorge. 1988. "Frontera, misiones y misioneros en Chile y Araucanía (1600-1900)", en Pinto, Jorge, Casanova, Holdenis, Uribe, Sergio, y Matthei, Mauro, Misioneros en la Araucanía, 1600-1900. Un capítulo de historia fronteriza en Chile, Temuco, Ediciones Universidad de La Frontera, p. 99.

${ }^{16}$ Pinto, Jorge. 1991-92. "Etnocentrismo y etnocidio. Franciscanos y jesuitas en la Araucanía, 1600-1900", en Nütram, Año VII, N²4, pp. 10-11.

${ }^{17}$ El eminente historiador eclesiástico Lino Gómez Canedo ha afirmado acertadamente que no es posible atribuir a la orden franciscana una política indigenista oficial, uniforme y permanente, ya que a pesar de los principios teológicos que estimulaban su labor y que servían de marco general para su accionar en cada región del Nuevo Mundo, los hombres del hábito café procuraron solucionar cada caso en su situación concreta. Véase Gómez Canedo, Lino. 1976. "Evangelización y política indigenista. Ideas y actitudes franciscanas en el siglo XVI". En Estudios sobre política indigenista española en América, tomo II, Valladolid, Universidad de Valladolid, p. 21. También Gómez Canedo, Lino. 1988. "Aspectos característicos de la acción franciscana en América". En Actas del II Congreso Internacional sobre los franciscanos en el Nuevo Mundo, Madrid, Editorial Deimos, p. 441.
} 
caciques en torno al puerto fluvial de Valdivia ${ }^{18}$; Rodrigo Escribano Roca, quien recalca el papel de mediadores jugado por los seráficos en la región cordillerana ${ }^{19}$; de Ignacio Chuecas Saldías, quien hace hincapié en el rol alfabetizador de los padres franciscanos dejando entrever la posibilidad de que dicha actividad educativa se haya hecho extensiva a algunas mujeres nativas $^{20}$; y de Cristián Leal Pino y Andrés Quitral Manosalva, quienes en un interesante estudio buscan resaltar la metamorfosis del paradigma interventor franciscano a partir de la segunda mitad del siglo XVIII, pasando de un accionar prioritariamente evangelizador a otro de eminente occidentalización de los nativos ${ }^{21}$.

La investigación se sustentó en un análisis pormenorizado de fuentes editadas, así como en la pesquisa, transcripción y estudio de la información proporcionada por documentos depositados en repositorios institucionales como el Archivo Nacional de Santiago o el Archivo Francisano. Contando en la actualidad con una amplia bibliografía sobre las relaciones de mapuches y misioneros, el mayor aporte consiste en realizar una lectura renovada y crítica de las fuentes.

\section{Contexto}

Corría el año 1739 cuando Martín de Recabarren, oidor de la Audiencia de Chile, expresó su disconformidad con los medios pacíficos y sacramentales usados por los padres de la Compañía de Jesús entre los nativos del sur de la gobernación. Desde su perspectiva, los métodos empleados para la evangelización exigían un cambio acorde con las circunstancias, ya que:

"jamás las misiones de la tierra han podido tener mas logro, por que nunca han sido sujetados estos indios á campaña, ni doctrina en la forma que en los demas dominios de las Indias que los socilita, ningun adulto sufre ni a sufrido la corrección de su Parroco, repugnando los padres aun la de sus hijuelos, i sin diciplina, como se conseguirá la puntual asistencia a ser enseñados"22.

Convencido de que no había otro camino para poner fin a tan dilatado conflicto, respaldó el uso de la fuerza mediante el brazo armado del ejército, pues el “Católico deseo" del rey gastaba

\footnotetext{
18 Poblete, María. 2009. "Prácticas educativas misionales franciscanas, creación de escuelas en territorio mapuche y significado de la educación para los mapuche-huilliche del siglo XVIII y XIX", en Espacio Regional, Vol. 2, N 6, Osorno, p. 25. También Poblete,, María. 2008. "Mapuche-huilliches e hispano-criollos en Valdivia. Cartas de petición y procesos de articulación en el periodo colonial tardío", en Cultura, Hombre, Sociedad, Vol. 15, № 2, Temuco, p. 57.

${ }^{19}$ Escribano, Rodrigo. 2015. "Frailes y cautivas. Un caso de negociación interétnica en la frontera hispano-mapuche (1752-1760)" en Cañedo-Argüelles, Teresa (coord.), América. Cruce de miradas, Vol. 2, Alcalá de Henares, Universidad de Alcalá/Asociación Española de Americanistas, p. 567.

${ }^{20}$ Chuecas, Ignacio. 2016. "India salvaje, letrada y litigante. Una mujer indígena de la 'tierra adentro' ante la justicia colonial. Chile, 1760", en Revista Historia y Justicia, N 6, Santiago, pp. 261-262.

${ }^{21}$ Leal y Quitral. 2017. “Evangelización y occidentalización en la frontera sur del Reino de Chile”, pp. 162-163.

${ }^{22}$ Archivo Nacional de Santiago. Fondo Antiguo (en adelante AN, FA), Informe al Rey sobre los medios de reducir a los indios de Chile y conservar la quietud del Reino. 1739,Vol. 32. Pieza 3. fs. 23-23v.
} 
"ecsorbitantes millares" hasta el consumo sin fin de la Real Hacienda, acusando, de paso, que la campaña sacramental de los jesuitas se debía simplemente al "agasajo que interviene para que el Padre condescienda en el Bautismo del hijo porque ejecutandose por personas tan espirituales u doctas no encontrarán el vicio detestable de la simonía"23.

Empero, sus clamores encontraron oídos sordos en la Corona, la que se mantuvo firme en la prosecución del camino de la paz (objetivo caro a los ilustrados), viéndose reflejado este ideal en las capitulaciones del Parlamento de Negrete de $1726^{24}$, y en los celebrados en Tapihue en $1738^{25}$ y $1746^{26}$, donde se ratificaron sendas paces en las que se establecieron cláusulas relativas a la admisión de misioneros dentro de los cuatro vutanmapus ${ }^{27}$. En un escenario de tensiones e intereses contrapuestos, la paz representó una derrota para aquellos funcionarios que veían en la guerra la solución al conflicto permanente. Entre esas voces se contaron no pocos gobernadores de Chile, como el propio José Antonio Manso de Velasco, quien validó el uso de la vía militar, declarando - en el mismo año que Recabarren-que el único medio para reducir a los naturales "a la vida sociable es el poderoso brazo de V.M., al estruendo del cañón y del fusil que tanto temen" ${ }^{28}$. Posteriormente, en diciembre de 1756, el gobernador Manuel de Amat y Junient celebró el Parlamento de Salto de la Laja, que significó un nuevo revés para aquellos que defendían la alternativa armada. De esta instancia emergió un actor que hasta entonces había desempeñado un papel menor en la tarea misional, los Franciscanos del Colegio de Propaganda Fide de Chillán. El Colegio había sido fundado en aquella ciudad en junio de 1756, y a poco andar fueron convocados por el gobernador al parlamento general, en el cual, "a instancias de los mismos indios", solicitaron se adjudicase al Colegio "el Pire-vutha-mapu ó cantón que corre por entre las cordilleras nevadas, terreno que ocupa la nación llamada comúnmente Pehuenche"29. Dando cuenta de esto Mariano Martí, secretario de Cámara, escribió:

"Y a poco rato despues de haber dado principio pidieron al señor Presidente los Indios Pehuenches audiencia, diciendo que tenian que tratar una materia muy importante; y concediéndoles con suspension de los demas, dijeron: que querian por sus PP. Misioneros a

\footnotetext{
23 Ibíd, f. 23v.

24 "Parlamento de Negrete de 1726", en Zavala, José (editor). 2015. Los Parlamentos Hispano-Mapuches, 1593-1803: textos fundamentales, Temuco, Ediciones Universidad Católica de Temuco, pp. 217-228.

25 "Parlamento de Tapihue de 1738", en Ibíd., pp. 235-244.

26 "Parlamento de Tapihue de 1746", en Ibíd., pp. 245-253.

27 Guillaume Boccara los define como "distrito político macrorregional compuesto por diversos ayllarewe"; véase Boccara, Guillaume. 2007. Los vencedores. Historia del pueblo mapuche en la Época Colonial, Santiago, IIAM, p. 414. 28 "Carta de Manso de Velasco al rey de España. Concepción. 28 de febrero de 1739", en Barros Arana, Diego. 1886. Historia General de Chile, tomo VI, Santiago, Rafael Jover, p. 102.

${ }^{29}$ Ascasubi, Miguel de, OFM. 2007. Informe cronológico de las misiones del Reino de Chile, hasta 1789, PAF, № 49, Santiago, p. 9.
} 
los de la Religion Seráfica de N.P.S. Francisco, explicándose en su vulgar término Pucari Patiru, padres caris." ${ }^{30}$

Manuel de Amat respondió a esta petición con sorpresa. Que los pehuenches hayan hecho tal solicitud eclipsaba las opiniones del oidor Martín de Recabarren y del propio Manso de Velasco, y dio nuevas esperanzas a la tarea de conversión. Este fue el inicio de las tareas franciscanas en la frontera hispano-mapuche, las que no contaron con la simpatía de todos los funcionarios ilustrados, pero que se habían vuelto necesarias bajo la sombra de un nuevo contexto de incentivo y aumento del comercio interétnico ${ }^{31}$. Para comprender esta situación debemos retrotraernos al Parlamento de Negrete en 1726, en el cual la Corona renunció a la conquista de la Araucanía focalizándose en las relaciones de intercambio para el abastecimiento de mercados. La decisión de regular el comercio con el propósito de brindar cierto grado de igualdad en las condiciones del juego fronterizo implicó acabar con el monopolio de los capitanes de amigos, estimular la conformación de ferias para "conchavos" y pactar la participación de los religiosos ${ }^{32}$. Los misioneros, de este modo, siguieron en el ruedo, más aún cuando los mapuches aceptaron la presencia de los padres seráficos posteriormente a 1756, convirtiéndose estos en unos verdaderos passeurs ${ }^{33}$, go-betweens ${ }^{34}$ o intermediarios culturales capaces de influir las dinámicas de poder en las relaciones entre el mundo indígena y europeo ${ }^{35}$, desempeñando en el caso mapuche un renovado papel en la política de alianzas en pro del comercio y la paz.

\footnotetext{
30 "Testimonio escrito por Mariano Martí. Santiago. 9 de marzo de 1758", en Lagos, Roberto. 1908. Historia de las misiones del Colegio de Chillán, vol. 1, Barcelona, Herederos de Juan Gili Editores, pp. 108-109.

31 Inostroza, Iván. 2014. "El circuito colonial hispano-mapuche, 1660-1710", en Pinto, Jorge, e Inostroza, Iván, Expansión capitalista y economía mapuche: 1680-1930 y Tres Razas, 1887, Temuco, Ediciones Universidad de la Frontera, pp. 21-41.

32 "Parlamento de Negrete de 1726", en Zavala. 2015. Los Parlamentos Hispano-Mapuches, p. 222.

${ }^{33}$ Berta Ares y Serge Gruzinski definen a los mediadores culturales como "aquellos agentes sociales que, desde una posición a menudo liminal y a caballo entre culturas, favorecieron las transferencias y el diálogo entre universos aparentemente incompatibles, elaborando mediaciones muchas veces insólitas y contribuyendo así a su articulación y a la permeabilización de sus fronteras". Véase Ares, Berta y Gruzinski, Serge (coords.). 1997. Entre dos mundos. Fronteras culturales y agentes mediadores, Sevilla, Consejo Superior de Investigaciones Científicas, p. 10.

${ }^{34}$ Metcalf, Alida. 2005. Go-betweens and the colonization of Brazil, 1500-1600, Austin, University of Texas Press, p. 2.

${ }^{35}$ En el espacio fronterizo bonaerense del siglo XIX, la investigadora Silvia Ratto distingue entre los intermediarios que actuaban a nivel institucional, por un lado, y aquéllos que lo hacían de modo más informal. Esta dicotomía es igualmente válida para la frontera colonial mapuche de Chile, donde lenguaraces, misioneros, mercaderes, oficiales reales y demás integrantes de los tipos fronterizos desempeñaron un papel crucial en la interacción política, comercial y cultural que enlazó a los habitantes de ambos bordes de dicho curso fluvial. Véase Ratto, Silvia. 2005. "Caciques, autoridades fronterizas y lenguaraces: intermediarios culturales e interlocutores válidos en Buenos Aires (primera mitad del siglo XIX)", en Mundo Agrario. Revista de estudios rurales, Vol. 5, № 10. También Enrique, Laura. 2012. "Aportes de los 'intermediarios culturales' en la conformación de los paisajes fronterizos del norte de la Patagonia a fines del siglo XVIII", en Memoria Americana, Vol. 20, № 2, Buenos Aires, p. 257.
} 


\section{Territorio y dominio}

El problema del uso efectivo del territorio comenzó a ser un tema candente dentro de la corte madrileña bajo el contexto del surgimiento de dos grandes potencias, la Francia de Luis XIV y la monarquía parlamentaria inglesa. Esto generó un afán de aseguramiento territorial con el envío de expediciones, ora científicas ora militares, y la gestación de reformas que fueron el resultado - asegura Puig-Samper- de una serie de factores políticos (entre los que podemos citar la delimitación de fronteras y el control de las incursiones navales rivales), económicos (el aumento del comercio, el control del contrabando o la mejora de la explotación mineral) y demográficos (crecimiento poblacional y necesidad de una nueva cartografía americana) ${ }^{36}$. En otras palabras, los límites del imperio colonial, sus fronteras, constituyeron una preocupación constante que intentaron superar los regentes Borbones durante el siglo XVIII. En la práctica, las fronteras del dominio indiano se configuraron como zonas porosas, sin delimitación fija, en donde se gestaron intersecciones culturales de intercambio que fueron más allá del simple comercio, contrabando o de los tratos políticos entre hispanos e indígenas ${ }^{37}$. Las fronteras se formaron desiguales y cada una con distinta significación, sujetas a dinámicas de cambio que afectaron a cada una de sus partes, lo que dotó a los límites fronterizos de gran diversidad, flexibilidad y dinamismo. Fueron por sobre todo espacios difusos, de una permeabilidad derivada "de las prácticas cotidianas, de la concurrencia jurisdiccional y de las interacciones inter/transfronterizas" 38 .

Gabriel Guarda sostiene que durante el periodo colonial el reino de Chile tenía establecidas sus fronteras en la costa y en el sinuoso espacio próximo al río Biobío: en los mares rondó el adversario extranjero, y en el sur de la capitanía, por tierra, se situó el enemigo doméstico, los mapuches ${ }^{39}$. Durante el siglo XVIII rusos, franceses e ingleses avanzaron sostenidamente por las extensiones de América Septentrional, dejando en evidencia la debilidad de la dilatada frontera española en el Nuevo Mundo. Al sur de la línea ecuatorial las embarcaciones británicas se internaron en aguas del Pacífico para saquear y destruir poblaciones y naves, localizar y ocupar espacios de aprovisionamiento para los navíos, y tratar de establecer alianzas con los nativos a fin de socavar el poderío español ${ }^{40}$. De dimensiones incontrolables y con numerosos accesos al libre tránsito, la costa se tornó vulnerable a los embates de cualquier potencia enemiga, por lo que el litoral chileno adquirió una importancia geoestratégica dentro de los

\footnotetext{
${ }^{36}$ Puig-Samper, Miguel. 2011. "Las expediciones científicas españolas en el siglo XVIII", en Canelobre, № 57, p. 20.

37 Burke, Peter. 2010. Hibridismo cultural, Madrid, Akal ediciones, p. 120.

${ }^{38}$ Mantecón, Tomás y Truchuelo, Susana. 2016. "La(s) frontera(s) exteriores e interiores de la Monarquía Hispánica: perspectivas historiográficas", en Historia Crítica, № 59, Bogotá, p. 22.

${ }^{39}$ Guarda, Gabriel. 1990. Flandes Indiano. Las fortificaciones del Reino de Chile, 1541-1826, Santiago, Ediciones de la Universidad Católica, p. 2.

${ }^{40}$ Stewart Stokes, Hamish. 2000. Del Mar del Norte al Mar del Sur: navegantes británicos y holandeses en el Pacífico suroriental, 1570-1807, Valparaíso, Editorial Puntángeles, p. 82.
} 
márgenes del imperio ${ }^{41}$. Los hispano-criollos que habitaban el reino de Chile siempre concibieron este territorio como el área de expansión natural del dominio imperial al sur del continente, por lo que la independencia de los indígenas era ponderada como un problema para la soberanía política y territorial de la gobernación y, por extensión, del Virreinato peruano ${ }^{42}$. En otras palabras, su importancia residía en su localización geográfica como territorio periférico y baluarte de defensa de otros espacios de mayor peso económico y político, como el Perú. En 1695 fray Bernardo Carrasco, obispo de Santiago, hizo patente esta inquietud al informar sobre la presencia de una doble frontera, una interna y otra exterior, que generó una alerta continua en las colonias, teniendo episodios críticos en la "guerra interior del enemigo de tierra" y en la guerra "exterior del pirata inglés" ${ }^{43}$. En ambos frentes la situación hispana era precaria. Ante tan abrumadora circunstancia, no faltaron las voces que hicieron un llamado a someter a las indómitas poblaciones aborígenes del sur de Chile por medio del fuego y la espada. Sin embargo, limitaciones infraestructurales y económicas determinaron que primara la vía pacífica. El alicaído estado de la economía, situación que se venía arrastrando desde la centuria anterior, impuso sus condiciones, de modo tal que se optó por establecer y perpetuar una paz duradera a fin de eludir el gasto asociado a la guerra. España evitó siempre sostener dos frentes abiertos en su extenso imperio: los costes de la defensa, tanto en el Viejo Mundo como en el Nuevo, estaban colocando cargas insoportables sobre los hombros de una Real Hacienda empobrecida.

El frente externo dependía de factores y motivaciones ligados a un sistema de economíamundo en proceso de consolidación, en el que Francia e Inglaterra disputaban la hegemonía del comercio europeo y americano ${ }^{44}$. A finales del siglo XVII América ya formaba parte de un mundo integrado en donde las rivalidades de las monarquías europeas trascendían el océano hasta alcanzar a las sociedades coloniales americanas, forjándose "nuevas relaciones, tanto trasatlánticas como hemisféricas, como respuesta a las exigencias combinadas, a menudo contradictorias, del comercio y la guerra" ${ }^{45}$. A esas alturas se habían forjado nuevas potencias

\footnotetext{
${ }^{41}$ Guarda. 1990. Flandes Indiano, pp. 2-3.

42 Gándara, Natalia. 2016. "Representaciones de un territorio. La frontera mapuche en los proyectos ilustrados del Reino de Chile en la segunda mitad del siglo XVIII", en Historia Crítica, Bogotá, N59, p. 63.

${ }^{43}$ Carta de Fr. Bernardo Carrasco al Rey, de 12 de septiembre de 1695. En Lizana, Elías (ed.). 1919. Colección de documentos históricos del Arzobispado de Santiago (en adelante CAAS). Cartas de los obispos al rey, 1564-1814, tomo I, Santiago, Imprenta Laguna \& Co., p. 406.

${ }^{44}$ Immanuel Wallerstein señala que en la transición del siglo XVII al XVIII, Francia obtenía plata proveniente de México a través de España, mientras que Inglaterra llegó a monopolizar el oro proveniente de Brasil por medio de Portugal; véase Wallerstein, Immanuel. 2011. The modern world-system: mercantilism and the consolidation of the European world-economy, 1600-1750, Berkeley, University of California Press, p. 276. Para un debate sobre la validez del concepto "sistema-mundo" como categoría de análisis histórico, véase Osorio, Jaime. 2015. "El sistema-mundo de Wallerstein y su transformación. Una lectura crítica", en Argumentos, Año 28, N 77, México D.F, pp. 131-154. ${ }^{45}$ Elliott, John. 2011. Imperios del Mundo Atlántico. España y Gran Bretaña en América (1842-1830), Madrid, Taurus Ediciones, p. 331.
} 
en el Viejo Continente que desestabilizaron el equilibrio occidental dominado por el Imperio español, por lo que la Península Ibérica perdió el monopolio sobre el Nuevo Mundo que le había sido conferido por el papa Alejandro VI en $1493^{46}$. Estas potencias emergentes se empeñaron en incrementar el comercio, tan desatendido por los españoles. La expansión de Inglaterra a fines del siglo XVII tuvo el objetivo de formar un imperio comercial y marítimo, lo que la llevó a rivalizar en la costa Pacífica y Atlántica con los españoles. No solo eso, los lances en las costas del sur de Chile y la captura de territorios de Centro América, de una serie de islas del Caribe y de las Guayanas por británicos, franceses y holandeses, horadaron aún más el dominio hispano y plagó el mar de bucaneros, piratas e incursiones enemigas. De esta forma, comercio y piratería tendieron a ser sinónimos en el albor del siglo XVIII, y "bucaneros, mercaderes y plantadores se convirtieron en cómplices tornadizos en la empresa de despojar al Imperio español de sus bienes" ${ }^{47}$.

Hacia mediados del siglo XVIII las fronteras en América se habían transformado en zonas de miedo psicológico ante una eventual incursión extranjera o un posible alzamiento general de los nativos. El mayor recelo lo generaba una eventual alianza entre indígenas y potencias europeas rivales, muy especialmente los británicos, frente a lo cual sería muy difícil sostener contraofensivas exitosas. Así, por ejemplo, investigaciones recientes demuestran la inquietud que generó entre 1671 y 1779 la inminente instalación de colonias inglesas en las costas más australes de la Patagonia Occidental, territorio comprendido entre la provincia de Chiloé y el confín americano ${ }^{48}$. Adelantándose a esta situación, los Borbones actuaron con urgencia y resolvieron consolidar el control sobre las áreas periféricas a través de su política reformista. De esta manera, buscaron nuevas formas de relacionarse con sociedades indígenas que hasta ese entonces habían preservado su autonomía, destacando entre todas los mapuches del sur de Chile.

\section{El colegio de propaganda respecto al peligro doméstico}

Hacia 1700 el obispo de Santiago, Francisco de la Puebla Gonzales, manifestaba su descontento por los escasos logros y el poco avance de la evangelización, pero a diferencia de los militares y administradores, achacaba la causa de aquel estancamiento a la participación y corrupción de los seculares ${ }^{49}$. Lo acaecido en 1723 con la rebelión mapuche le daría la razón al obispo, tornándose evidente que el comportamiento cerril de los seculares rompió la paz que volvería

\footnotetext{
46 lbíd., pp. 332-333.

47 lbíd., p. 338.

48 Urbina Carrasco, Ximena. 2018. "Los 'papeles de Londres' y alertas sobre ingleses. Chiloé y las costas de la Patagonia Occidental ante los conflictos entre España e Inglaterra: siglos XVII y XVIII", en Mélanges de la Casa de Velázquez. Nouvelle série, $\mathrm{N}^{\circ}$ 48, vol. 2, ciudad, pp. 235-264.

${ }^{49}$ Carta del Obispo de Santiago a Su Majestad. 1700. Archivo Nacional, Colección Morla Vicuña (en adelante AN, CMV). Vol. 3. Pieza 3. fs. 3v-4.
} 
luego de tres sinuosos años ${ }^{50}$. En el alzamiento - nos dice Carvallo y Goyeneche- los mapuches batallaron contra un gobierno despótico ${ }^{51}$. El historiador dieciochesco aclara que en absoluto se obedecieron leyes y reglas por parte del gobierno civil de la frontera, volviéndose demasiado pesado para los naturales el yugo de los gobernadores ${ }^{52}$. Carvallo y Goyeneche deja en evidencia que el aparato civil que resguardaba la frontera se encontraba en tal estado de corrupción e insuficiencia, que tras la rebelión mapuche de 1723 no solo habían quedado destruidas las plazas fuertes emplazadas al meridión del Biobío, ya que también se había perdido la confianza en las instituciones fronterizas ${ }^{53}$. De esta manera, luego de la rebelión y una vez concertadas las paces en el Parlamento de Negrete de 1726, la misión evangélica se posicionó en la vereda opuesta a aquellas circunstancias que habían originado el alzamiento, teniendo de ahora en adelante los padres conversores la tarea de actuar como observadores en ferias anuales sin dejar sus habituales tareas misioneras al interior de la tierra indígena. En la segunda mitad del siglo XVIII algunas autoridades pensaron en el agotamiento y corrupción de los recursos seculares, y pese a que no había un consenso entre los administradores respecto a las alternativas de la vía armada o pacífica, la opinión mayoritaria se inclinaba por reforzar la vía religiosa. En 1730 el obispo de Santiago, Alonso del Pozo y Silva, informó al rey sobre la conveniencia de refundar algunas misiones suprimidas por el retroceso y destrucción de los fuertes fronterizos. El obispo sugirió continuar con la política misional jesuita suspendida por la rebelión, la cual era apoyada por las plazas fuertes fronterizas que tenían por función ser "assilo para los missioneros" ${ }^{54}$.

En esa misma línea y mientras servía como gobernador del reino, en 1736 Manuel de Salamanca respondió ante la Real Audiencia una cédula de diciembre de 1733, defendiendo:

“(...) la importancia o necesidad que hay para que se restablezca las misiones entre ellos [los naturales], debo decir a vuestra Magestad que no parece materia digna de duda, sabiendo es otro el católico y Real animo de vuestra Magestad que el que conozcan a Dios todos sus vasallos, pasando al más intimo sentimiento veer perderse tantas almas, como cada día se pierden asi de parbulos que mueren sin bautismo, como de algunos adultos que en el articulo de la muerte claman por falta de obreros evangelicos, sin que puedan socorrerles en el sistema de no tener dentro de sus tierras doctrineros que auxilien a los unos, y a los

\footnotetext{
50 Sobre las características de esta rebelión véase Casanova, Holdenis. 1987. Las rebeliones araucanas del siglo XVIII. Mito y realidad, Temuco, Ediciones Universidad de La Frontera.

${ }^{51}$ Carvallo y Goyeneche, Vicente. 1875. Descripción Histórico-Jeográfica del Reino de Chile, tomo II. Colección de Historiadores de Chile y Documentos Relativos a la Historia Nacional (en adelante $\mathrm{CHCH}$ ), tomo IX, Santiago, Imprenta de "La Estrella de Chile", p. 237.

52 lbíd., p. 238.

53 Respecto a esto, Carvallo y Goyeneche comenta que en la frontera conoció pocos personeros que no fueran "hombres perversos" y “mui pocos (...) sin vicios detestables". Ibíd., p. 237.

${ }^{54}$ Carta de D. Alonso del Pozo y Silva al Rey.17 de marzo de 1730. En Lizana. 1919. CAAS, tomo I, pp. 483-484.
} 
otros, por lo que juzgo excenta para el daño tan irreparable la providencia de que de nuevo se introduzgan Misioneros a las tierras de los indios" ${ }^{\prime 55}$.

De lo anterior se puede inferir que Salamanca buscó volver al equilibrio fronterizo que había reinado entre hispanos y mapuches desde 1690 hasta 1723 gracias a los parlamentos y la vía pacífica de evangelización ${ }^{56}$. Sin embargo, este renovado impulso no coincidió con una reformulación del método jesuita a la luz de los nuevos tiempos, por cuanto las disgregadas misiones volantes, años más tarde, siguieron siendo el único modelo de evangelización puesto en práctica en la frontera. Haciendo una evaluación crítica de esto Manuel de Alday, obispo de Santiago, informó al rey en 1755 que las misiones jesuitas resultaron "ser inútiles" en varios pueblos a la orilla del río Biobío, "y que en las de Tucapel y Toltén, que existen en el interior de los indios, no se logra más fruto que el de bautizar los párvulos, sin que haya quien penetre lo más recóndito de sus tierras para predicarles el Evangelio" ${ }^{17}$. Lo que puso en entredicho el obispo fue la cruzada bautismal en pro de la salvación de las almas, pero sin prever una real conversión de los naturales ${ }^{58}$. Para gran parte de las Órdenes confesionales no jesuitas la conversión no era un mero acto de cambio de filiación religiosa a través del sacramento del bautismo, ya que ello también demandaba una alteración del modus vivendi de los sujetos, quienes debían seguir las pautas de conducta de los hombres que habían encabezado su proceso de conversión: para ser buenos cristianos no bastaba con la fe, era necesario actuar como seres virtuosos ${ }^{59}$. Claramente, una de las pocas salidas conciliadoras para mejorar el contacto estaba resultando desventajosa, urgiendo un cambio en la vía de cristianización.

En suma, para la segunda mitad del siglo XVIII la administración secular y los misioneros estaban siendo refutados, la primera por no ser capaz de mantener las relaciones armónicas y un ejército acorde, y los segundos por los escasos resultados en la cristianización a costa del erario regio. Certero es el comentario de José Perfecto de Salas, oidor de Santiago y digno representante del espíritu ilustrado, acerca del estado de la frontera y los medios empleados para su pacificación:

“(...) la experiencia de dos siglos ha hecho ver que los medios hasta aquí practicados no han tenido proporción con el fin, pues por el de la guerra no se ha avanzado un palmo de tierra más allá de la barrera que siempre han tenido los indios, y el de la predicación no ha cogido

\footnotetext{
${ }^{55}$ Carta de Manuel de Salamanca a S.M. 26 de septiembre de 1736. AN, CMV. Vol. 5. Pieza 85. fs. 316-316v.

56 Foerster. 1996. Jesuitas y Mapuches, p. 274.

${ }^{57}$ Carta del Obispo electo D. Manuel de Alday al rey. 18 de febrero de 1755. En Lizana. 1919. CAAS, tomo I. p. 507.

58 Pinto. 1988. "Frontera, misiones y misioneros en Chile y Araucanía", p. 86.

59 Rex Galindo, David. 2014. “'Primero hombres, luego cristianos': un análisis sobre la conversión forzosa en la frontera de Texas", en Colonial Latin American Historical Review, (second series), Vol. 2, N 3, p. 413.
} 
el fruto de un indio perfectamente convertido, porque aunque lo parezca tal cual, siempre están con la mira al reclamo que tienen en sus tierras de libertinaje que profesan" ${ }^{\prime \prime 0}$.

La alternativa evangelizadora se configuró en 1756 con el establecimiento del Colegio Fide en Chillán ${ }^{61}$, desde donde rápidamente se alzó la voz contra la otra fuerza de cristianización, los jesuitas. Una de las primeras observaciones a la forma de trabajo de la Compañía de Jesús, además de las misiones volantes en sí mismas, fue el de la dispersión del poder misional ignaciano. El informe de Ascasubi nos dice que la "dilatación" de la obra jesuítica era contraria a los buenos resultados, señalando que poco o nada podían hacer con las numerosas parcialidades valiéndose solo del instrumento de las correrías ${ }^{62}$. Los franciscanos de Propaganda, por el contrario, abogaron por un método de "profundidad", concentrando los esfuerzos en poblaciones bien establecidas y controladas desde donde podrían garantizar la conversión. Los hombres del hábito café plantearon la necesidad de reducir el territorio bajo responsabilidad de cada misión, buscando ejercer un control efectivo sobre las parcialidades elegidas y dando primacía a la dimensión educativa por sobre la ritual-sacramental, como hacían los jesuitas. ${ }^{63} \mathrm{El}$ antropólogo José Manuel Zavala argumenta que una de las principales diferencias entre franciscanos y jesuitas estribaba en que los primeros no se conformaban únicamente con las visitas anuales de evangelización puesto que su objetivo era tratar de crear misiones permanentes ${ }^{64}$. Los sacerdotes del Colegio creyeron en un método reduccional que debía implementarse poco a poco siguiendo algunos pasos necesarios: acercamiento, instrucción, conversión y reducción ${ }^{65}$. Una vez establecido el Colegio en la ciudad de Chillán,

\footnotetext{
60 Informe dirigido al rey sobre el reino de Chile. 1752, en Donoso, Ricardo. 1963. Un letrado del siglo XVIII, el doctor José Perfecto de Salas, Buenos Aires, Universidad de Buenos Aires, Facultad de Filosofía y Letras, p. 127.

${ }^{61}$ Al cotejar investigaciones recientes se desprende que la fundación del Colegio de Propaganda Fide de San Ildefonso de Chillán tuvo un propósito doble. Por una parte, el bien conocido objetivo de evangelizar a los pehuenches $y$, tras la expulsión de los jesuitas, a gran parte de las agrupaciones indígenas que se repartían en los territorios meridionales del reino de Chile, todo esto dentro del marco de las reformas borbónicas que buscaban establecer un modelo misional y pastoral innovador más orientado a la occidentalización que a la enseñanza del cristianismo propiamente tal. En segundo lugar, la de responder a la necesidad de recuperar el control sobre las élites locales que habían fomentado durante todo el siglo XVII una creciente autonomía mediante el afianzamiento de redes de patronazgo y clientelares. Véase Leal y Quitral. 2017. "Evangelización y occidentalización en la frontera sur del Reino de Chile", pp. 162-163; y Viñuela Pérez, Rebeca. 2015. "Los franciscanos del Colegio de Propaganda Fide de San Idelfonso de Chillán como mediadores políticos en la frontera araucana del siglo XVIII" en CañedoArgüelles, Teresa (coord.), América. Cruce de miradas, Vol. 2, Alcalá de Henares, Universidad de Alcalá/Asociación Española de Americanistas, pp. 585-586.

62 Ascasubi. 2007. Informe cronológico de las misiones del Reino de Chile, p. 24.

63 Poblete. 2009. "Prácticas educativas misionales franciscanas", p. 25.

${ }^{64}$ Zavala. 2008. Los mapuches del siglo XVIII, p. 115. Véase también Viñuela. 2015. "Los franciscanos del Colegio de Propaganda Fide de San Idelfonso de Chillán", p. 591. También Pinto. 1988. "Frontera, misiones y misioneros en Chile y Araucanía", pp. 69-70.

65 Nicoletti, María. 2002. "Jesuitas y Franciscanos en las misiones de Norpatagonia. Coincidencias y controversias en su discurso teológico", en Anuario de Historia de la Iglesia, vol. 11, Pamplona, p. 225.
} 
este se transformó en la casa matriz de todas las acciones que posteriormente se llevaron a cabo, consolidándose como el poder central de toda la obra misionera en la frontera, o la "armería" donde los "soldados de la milicia espiritual de la Sta. Iglesia deben venir á armarse y fortaleserse con el escudo impenetrable de el zelo de la honra de Dios" 66 .

Una vez establecido su centro de operaciones, los franciscanos se repartieron entre las parcialidades pehuenches siguiendo los acuerdos alcanzados en el Parlamento de Salto de la Laja. El compromiso de la administración regia con las tareas seráficas queda en evidencia en el interés por asegurar los territorios ya pacificados de la frontera. Primero, por su ubicación geográfica frente al valle central y la estratégica Isla de la Laja, espacio esencial para la penetración hispana al vutanmapu de los llanos. Segundo, porque durante el siglo XVIII pehuenches y españoles realizaron una ingente actividad comercial ${ }^{67}$, que consistió en el intercambio de bienes de interés para ambas partes a través del trueque ${ }^{68}$. Tercero, y no menos trascendente, fue la posición estratégica del área pehuenche, ya que aquella zona cordillerana se había convertido en un antemural contra las incursiones de las tribus guerreras que pretendían adentrarse a través de los pasos andinos al valle central de Chile desde las pampas ${ }^{69}$. Finalmente, en la paz con los pehuenches se materializaron algunas de las más sustanciales políticas borbónicas de reactivación económica de las periferias, como lo fue el proyecto de ruta elaborado por Luis de la Cruz para unir Concepción con Buenos Aires, integrando el Pacífico con el Atlántico a través del tráfico terrestre. El plan fue descrito por Juan de Ojeda en 1803, y consistía en abrir un camino desde Concepción a través de los "países orientales" para la "exaltación de su comercio directamente deseado por el reino de Buenos Aires, sin el exhorbitante desvío i lejano rodeo de más de 160 leguas que padece por la vía de la ciudad de Santiago"70.

Que el Estado haya dejado en manos de los sacerdotes del Colegio de Propaganda la dirección apostólica de los pehuenches demuestra la importante trascendencia que había

\footnotetext{
${ }^{66}$ Copia del informe que hizo al señor presidente del Reino de Chile, José Gondar. 28 de septiembre de 1762. Archivo Franciscano del Colegio de Chillán (en adelante AFCC). Vol. 1. Doc. 79. f. 344.

${ }^{67}$ Casanova, Holdenis. 1988. "Presencia Franciscana en la Araucanía. Las misiones del Colegio de Propaganda Fide de Chillán (1756-1818)", en Pinto, Jorge, et al. Misioneros en la Araucanía, 1600-1900, p. 156.

68 Manuel de Amat y Junient dice en su informe al rey que “(...) comercian con los españoles a ciertos tiempos en determinados parages a las raíces de la Cordillera. El arreglo de su comercio es por conmutaciones cambiando unas especies por otras". Véase Amat y Junient, Manuel de. 1927. "Historia Geographica e Hidrographica con derrotero general correlativo al plan de el Reyno de Chile que remite a nuestro Monarca el señor don Carlos III su gobernador y capitán general don Manuel de Amat y Junient; ¿1760?", en Revista Chilena de Historia y Geografía, Tomo LII, N 56, Santiago, p. 372.

69 León, Leonardo. 1990. Maloqueros y conchavadores en Araucanía y las Pampas, 1700-1800, Temuco, Ediciones Universidad de la Frontera, p. 17.

70 Ojeda, Juan de. 1898. "Informe descriptivo de la frontera de la Concepción de Chile, por el coronel don Juan de Ojeda, 1803", en Anrique, Nicolás, Biblioteca Jeográfico-Hidrográfica de Chile (segunda serie), Santiago, Imprenta Elzeviriana, p. 285.
} 
alcanzado en la política colonial el incentivo de las relaciones interétnicas y comerciales pacíficas; ambas fueron las grandes áreas reforzadas por la administración a partir del Parlamento de 1726. Esto también deja en evidencia que se había perdido la confianza en el método misional ignaciano, quienes desde este momento tuvieron que enfrentar la rivalidad del sistema evangelizador desplegado por los franciscanos de Chillán, posicionándose estos últimos como la opción más compatible con las nuevas perspectivas monárquicas debido a su estrategia de conversión en "profundidad" (alcanzar una verdadera transformación de la cultura indígena y una total devoción a la fe Cristiana) en detrimento de una conversión en "extensión" (privilegiar el bautismo para la salvación de sus almas, como hacían los jesuitas). Los Borbones estaban encaminados en una política de asimilación de las poblaciones nativas rompiendo con el paradigma segregacionista que había imperado hasta entonces. Si antes una legislación protectora y la actividad misional española habían buscado mantener a la República de los Indios apartada de la República de los Españoles, ahora se alentaba que los indígenas adoptaran los hábitos y estilo de vida de los hispanos ${ }^{71}$.

Los frailes franciscanos valoraron la importancia del Colegio de Chillán y la trascendencia de las tareas misioneras que realizaban sus miembros, asunto expuesto por el padre José Gondar hacia 1756 en las siguientes líneas:

"Es Señor este Colegio medio tan precisamente necesario para las seraphicas misiones de infieles de este Reyno, que sin el ni otro tal como el, es imposible poder dar passo en ellas (a lo menos passo que dure) por la qual deseando (como lo supongo de su Xptianisimo zelo) el rey n.sr. (...) y V. señoria, este supremo Gobierno, y nosotros mismos, la verdadera combercion de estos miserables a nuestra Santa fee, y siendo por otra parte cierto (como lo es) que el que seriamente quiere el fin debe primero procurar y poner los medios eficazes para conseguirlos, de ay es que debemos todos procurar el que esta obra se concluya quanto antes" $^{\prime 2}$.

Apenas dos años después el mismo sacerdote escribía este esclarecedor pasaje:

"Ciertamente podemos decir con toda verdad: mesis quidem multa, operarii autem pauci. Y no con menos realidad podemos decir también: (parvuli petierunt panem, et non erat qui frangeret eis). Todos claman, fieles y infieles, por el pan de la divina palabra, y no ay quien se los pueda partir, ni repartir"73.

\footnotetext{
71 Wilde, Guillermo. 1999. “¿Segregación o asimilación? La política indiana en América meridional a fines del periodo colonial", en Revista de Indias Vol. LIX, N²17, Madrid, p. 634.

72 Copia del informe que hizo al señor presidente del Reino de Chile, José Gondar. AFCC. Vol. 1. Doc. 79. fs. $344-$ $344 \mathrm{v}$.

${ }^{73}$ Carta del P. José Gondar al P. Fray Antonio Herosa. 4 de mayo de 1758, en López, Atanasio. 1914. Cartas de los misioneros del Colegio de Chillán, Madrid, Archivo Ibero-Americano, p. 171.
} 
El padre Gondar se valió de un pasaje bíblico extraído del libro de Jeremías cuando dice que "Ios niños pidieron pan, y no había quien se los partiese" (parvuli petierunt panem, et non erat qui frangeret eis $)^{74}$. La analogía entre el mensaje del libro sagrado y la precaria situación espiritual de los indios no fue más que una crítica velada a los pobres resultados de la labor ignaciana.

Manuel de Amat y Junient, gobernador educado en el celo de la razón dieciochesca y prominente ilustrado ${ }^{75}$, sopesó las diversas necesidades que demandaba el desafío de la relación interétnica y las canalizó favoreciendo el desempeño del Colegio de Chillán, procurando el complemento de la asistencia espiritual (franciscanos) y armada (ejército fronterizo) en el juego fronterizo con los pehuenches ${ }^{76}$. De esta forma, el primer establecimiento para el apostolado se instaló al pie de los Andes para formar una entrada segura al Pirevutanmapu (el territorio cordillerano), fundándose el hospicio de Santa Bárbara en el paraje de Nekén ${ }^{77}$. Pese a no ser una casa misional propiamente tal, los frailes comenzaron la enseñanza de los niños indígenas persuadidos de que "los párvulos están en mejores disposiciones para el catecismo, y á que acostumbrados desde la tierna edad á cursar el camino de la justificación"78. Tanto Ascasubi como Gondar nos informan que uno de los primeros logros en el Hospicio fue la recepción de los hijos de los caciques principales y de los muchos que vinieron después "Ilegando á juntarse de familia por lo comun cinco ó seis"79.

Prontamente, y con motivo del viaje de exploración y estudio de Pedro Ángel de Espiñeira, en 1758 fue fundada la misión de Nuestra Señora del Pilar de Rarileuvú (Rainlevu) en Neuquén, "en el corazón de la tierra de la nación pehuenche, inmediata al Rio Nauquen, y al estero que llaman de Rarin-leubu de quien toma la denominación" ${ }^{80}$. En su informe el padre Gondar declaró que

"El motivo pues de haverse colocado esta mision de que voi hablando, en el paraje mencionado, fue por concurrir allí muchos indios á pasar el Imbierno, y refugiarse en los tiempos de las guerras que frequentemente suelen tener con los otros indios infieles

\footnotetext{
${ }^{74}$ Una buena versión de esta cita se encuentra en la traducción del padre Phelipe Scío de San Miguel de donde la recogemos. Véase Scío de San Miguel, Phelipe. 1793. La Biblia vulgata latina traducida en español, y anotada conforme al sentido de los Santos Padres y expositores Catholicos, tomo VII del Antiguo Testamento: Las phrofecías de Jeremías y sus threnos, las de Baruch, de Ezequiel y de Daniel. Valencia, Oficina de Joseph y Thomas de Orga, p. 283.

75 Rodríguez, Humberto. 1999. "Manuel de Amat y Junyent y la Navona de Lima: un ejemplo de diseño urbano barroco del siglo XVIII en el virreinato de Perú". Anales del Instituto de Investigaciones Estéticas. Vol. XXI. № 74-75, pp. 148-149.

${ }^{76}$ Casanova. 1988. "Presencia Franciscana en la Araucanía”, p. 205.

77 Rodríguez Tena, Fernando. 2003. El Colegio Apostólico de Chillán, Santiago, PAF, № 80, p. 10.

${ }^{78}$ Ascasubi. 2007. Informe cronológico de las misiones del Reino de Chile, p. 30.

79 Ibídem.

${ }^{80}$ Copia del informe que hizo al señor presidente del Reino de Chile, José Gondar. AFCC. Vol. 1. Doc. 79. f. 345v.
} 
Ilamados Huylliches sus confinantes. Sobre si podran ó no podrán havitar allí todo el año religiossos misioneros, ay diversos pareceres por las incomodidades (...); lo cierto es que hasta ahora no hemos podido hacer la experiencia, por la suma inopia de Religiossos que ha padecido este Colegio desde sus principios y actualmente esta padeciendo" ${ }^{81}$.

Del párrafo se desprende que la acción misionera franciscana no se limitó a las tareas de evangelización, ya que también se empeñaron en asegurar el bienestar temporal de los naturales, protegiéndolos del rigor del clima y resguardándolos de los embates provocados por la intromisión de otras etnias. Según las informaciones del propio fray José Gondar, a la misión concurrían todos los años algunos padres para saciar el requerimiento de los naturales. Esto, sin embargo, no se contradice con la iniciativa complementaria de los indígenas de procurar su propio bienestar, quienes de seguro se acercaban a los misioneros para aprovisionarse de determinados recursos mediante el comercio o hallar un refugio temporal frente a los embates del clima, las pestes y los conflictos intertribales ${ }^{82}$.

Una tercera misión se construyó en Rucalhue en 1759, a la que se llamó Nuestra Señora de la Purísima Concepción, pero tuvo una triste suerte al ser incendiada al año siguiente. Fue reconstruida posteriormente en Quilaco, parcialidad muy próxima a Santa Bárbara con numerosa población ${ }^{83}$. La última misión fundada entre los pehuenches fue la de Nuestro Padre de San Francisco en Lolco, en 1766, que se emplazó en un valle cordillerano no lejos del nacimiento del río Malleco. Al igual que la misión anterior tuvo un desafortunado final, ya que fue incendiada por los indígenas comarcanos en la rebelión mapuche de 1766, a los cuales se sumaron los pehuenches que arrasaron con todos los emplazamientos levantados en la cordillera ${ }^{84}$.

El alzamiento de 1766 fue, en parte, consecuencia del último intento de los jesuitas por reducir a los mapuches a pueblos, creyendo que aquello bastaría para evangelizar y civilizar a los infieles ${ }^{85}$. Representó, quizás, su derrota más grande antes de la expulsión que los afectó al año siguiente. Pero también jugó un importante papel el gobernador Antonio de Guill y Gonzaga, hombre de espíritu vacilante que desoyó las críticas de los franciscanos a una aventura fundacional apartada de toda la realidad. Decidido a dar al ejército un rol preponderante en el proyecto para acallar las voces que acusaban su ineficiencia en el control de los nativos, incrementó la presencia y movilidad de los soldados en el espacio fronterizo,

\footnotetext{
81 Ibíd., p. 347.

82 Agradecemos a David Rex Galindo el hacernos ver esta segunda posibilidad interpretativa de la cita documental.

83 Lagos. 1908. Historia de las Misiones del Colegio de Chillán, pp. 124-126.

${ }^{84}$ Casanova. 1988. "Presencia Franciscana en la Araucanía”, p. 162.

85 Pinto, Jorge. 1986. "Estudio Preliminar". Joseph de la Sala, Visita General de la Concepción y su Obispado por Fray Pedro Ángel de Espiñeyra, Chillán, Ediciones del Instituto Profesional de Chillán, p. 31.
} 
creando suspicacias entre los mapuches que alentaron la desconfianza y el resquemor ${ }^{86}$. El resultado fue la última gran rebelión mapuche del siglo XVIII, acontecimiento que terminó por sepultar la imagen de los jesuitas ante las autoridades locales y buena parte de la sociedad fronteriza. El eficiente desempeño del obispo Pedro Ángel de Espiñeira en la pacificación de los alzados fue lo que inclinó la balanza definitivamente del lado de los franciscanos. Con el extrañamiento de la Compañía de Jesús al año siguiente de la rebelión, los hijos de San Francisco de Asís adquirieron un protagonismo que no tuvo contrapeso en el escenario fronterizo, tomando el control total y definitivo de la evangelización entre los mapuches.

Para 1796 catorce misiones y un hospicio (Santa Bárbara) estaban en manos de los seráficos, tres de ellas herencia de la expulsión jesuita: Arauco, Valdivia y Mariquina. Los frailes del Colegio de Chillán habían salido airosos del conflicto de 1766. Antes del término de la rebelión y mediando una consulta real, el virrey Manuel de Amat y Junient les había dado su favor en la disyuntiva de tener que optar entre la guerra de exterminio propuesta por el gobernador Antonio de Guill y Gonzaga y la vía evangélica de la predicación planteada por el obispo Pedro Ángel de Espiñeira. Sin embargo, aunque el parecer del virrey favoreció al Colegio de Propaganda, no lo fue de la manera que imaginó el obispo de Concepción, ya que la postura de la autoridad limense enfatizaba la primacía que debía darse a la estrategia educativa ${ }^{87}$. Manuel de Amat postuló de este modo la vía educacional:

"El único arbitrio de suavidad que verdaderamente haría asequible este negocio es el que V.M. meditó muchos años hace si se hubiese puesto en planta y fue el de ir sacando con maña y sagacidad a los hijos de los principales regulos y caciques y conduciéndolos al Colegio de la ciudad de San Bartolomé de Chillan (...) [e] irlos instruyendo y enseñando las máximas políticas y cristianas" ${ }^{\prime 8}$.

En consecuencia, de ahora en adelante los esfuerzos evangelizadores se reforzaron con una nueva tarea, educar, método que funcionaría sobre la base de las misiones estables. Estas también sobrevivieron con buen pie a la revuelta indígena, siendo ratificadas en el Parlamento de Negrete de 1771, al que acudieron José Gondar y Pedro Ángel de Espiñeira; en el acta de junta reservada del parlamento se propuso que:

“(...) estando encargada por Su Majestad la conquista Espiritual de estos yndios con piadosas reflexiones de que no solo como rey Catholico sino también en consequencia de la Donación

\footnotetext{
86 Pinto. 1988. "Frontera, misiones y misioneros en Chile y Araucanía”, p. 73.

87 Pereira C., Karin. 2005. "Del Colegio al Seminario de Naturales: los franciscanos y la educación indígena en Chile, 1786-1811", en Millar Carvacho, René y Aránguiz Donoso, Horacio (eds.), Los franciscanos en Chile: una historia de 450 años, Santiago, Academia Chilena de la Historia, p. 173.

88 Informe del Virrey Manuel de Amat en que critica las medidas de Guill y Gonzaga. 1769. Biblioteca Medina, Manuscritos (en adelante BM, Ms). Tomo 292. Documento 8845. fs. 305-306.
} 
que le hizo la cede Apostholica de todos estos dominios procurar los medios mas combenientes a la predicación del Santo Evangelio, y combercion de estos infieles como lo habían mandado executar desde el principio de estas Conquistas (...)"189.

Más adelante se agrega:

"Que por lo que respecta al establecimiento de Misiones Tierras adentro si lo pidieren los Casiques, y prometiesen todos los seguros que preconise la Ley Real y se levantaren desentes Capillas, y Casa Competente para el Misionero, y Capitan de Amigos que indispensablemente ha de haber en el lugar de la Misión" ${ }^{\prime 00}$.

En el mismo Parlamento de 1771 se mandó que las labores educativas se llevaran adelante, al menos inicialmente, en algunas misiones $u$ hospicios, tal y como revela el acta de la junta:

"Que teniendo dispuesto que de cuenta de Su Magestad mantengan escuelas para la enseñanza de la Doctrina Christiana en las Plazas de Santa Barbara Santa Fee, y Arauco administradas por los Reverendos Padres Misioneros del Colejio Apostolico de Propaganda fide de Chillan, todos los casiques, y demas Yndios que quisieren despachar sus hijos a efecto de que sean enseñados y Doctrinados con los Verdaderos principios de nuestra Religion $(\ldots)^{\prime \prime 1}$.

A pesar del ahínco puesto en concretar este objetivo, recién en 1786 se estableció una institución seráfica dedicada netamente a la educación, cuya sede se erigió en Chillán. Antes de esta fecha, en 1774, por obra del gobernador Agustín de Juáregui, el colegio para hijos de caciques se situó en Santiago en un establecimiento de los expatriados jesuitas, pero los escasos resultados, producto, entre muchos factores, de la lejanía de las tierras infieles, determinó su traslado ${ }^{92}$. Esta institución educacional fue única en el reino, y su importancia residió en el método directo empleado para civilizar y cristianizar a jóvenes, combinando instrucción formal e informal ${ }^{93}$, reforzando la labor misional más allá del Biobío.

A lo anterior se suma lo que el historiador Roberto Lagos calificó como la utilidad de la misión para el orden civil. Esto se aprecia en el gran proyecto de Ambrosio O'Higgins por promover conversiones en toda la costa desde Concepción al sur, repoblando también Osorno, acto refundacional que habría de coronar la obra administrativa del gobernador ${ }^{94}$. Es ilustrativo, entonces, que en la reunión concertada con los indígenas comarcanos para la refundación de

\footnotetext{
89 "Acta de la Junta Reservada del Parlamento de Negrete de 1771", en Zavala. 2015. Los Parlamentos HispanoMapuches, p. 287.

90 Ibídem.

91 Ibíd., p. 293.

92 Pereira C., Karin. 2002. El Real Colegio de Naturales, Santiago, PAF, № 73, p. 41.

93 Ibíd., p. 14.

${ }^{94}$ Lagos. 1908. Historia de las misiones del Colegio de Chillán, p. 368.
} 
Osorno se haya hecho presente fray Francisco Javier Alday. Los buenos oficios del franciscano permitieron consolidar un pacto para el repoblamiento de la ciudad, ganando "para el uso de nuevos pobladores todo el terreno comprendido bajo la corriente del rio de las Damas, recinto inmenso y mas que suficiente para acomodar a todos los vecinos de una ciudad mas numerosa que lo que fue antiguamente" ${ }^{\prime 95}$. Se agrega luego que:

“(...) para que nada faltase, que pudiera ser de satisfaccion, se propuso en ella y aceptó solemnemente la introducción de dos Misiones, particular el mas importante de cuantos pudieron convenirse, pues pendia especialmente de su establecimiento la quietud y tranquilidad de aquellos Naturales, cuya consideracion por los Misioneros solo podía asegurar la duracion de lo tratado" ${ }^{\prime 96}$.

Se aprecia, por un lado, la gran capacidad de los seráficos de Chillán para generar una relación dialógica entre dos contrarios. Los franciscanos actuaron como go-betweens o intermediarios culturales, aprovechando de seguro la experiencia dejada por los jesuitas tras el extrañamiento. Por otra parte, es evidente la funcionalidad del Colegio para la mantención de las relaciones fronterizas pacíficas, contraponiéndose en todo al ejército. Es decir, el Colegio de Propaganda fue una institución primordial y necesaria para la gestación de diálogo pacífico entre un mundo ilustrado que buscó una nueva forma de tratar a sus colonias, y los indígenas que se adaptaron y desenvolvieron en los nuevos tiempos.

Los juicios de los propios naturales nos ayudan también a evaluar la importancia de la Propaganda Fide en la frontera. Una fuente importante para rastrear esto son los parlamentos fronterizos. Así, por ejemplo, en el Parlamento General de Lonquilmo realizado en 1784, un grupo de caciques hizo saber sus inquietudes en torno a las misiones y sus obreros. Don Ignacio Levihueque, gobernador de la misión de Santa Fe, expresó "que ha muchos días instaba por que aquella mision entregase a los Padres Predicadores Misioneros de la ciudad de Chillan y que ignoraba el motibo, porque los pribaban de aquel consuelo, siendo tan manifiestas las ventajas que asi en los Espiritual como en lo Temporal las resultarias (...)" $)^{\prime 97}$.

También el cacique Guegnir pidió se restituyese la misión de Lolco, "que lo propio prometió a aquel ofrecia a ellos que es noticiarlo y representar al señor Capitan General aumentando que esta seria una mision mui importante y mui buena, porque despues de otras ventajas mejoraba

\footnotetext{
95 Testimonio adjunto de noticias y providencias en la refundación de Osorno, 1794; en Lagos. 1908. Historia de las misiones del Colegio de Chillán, p. 369.

96 Ibídem.

97 "Parlamento de Lonquilmo de 1784", en Zavala. 2015. Los Parlamentos Hispano-Mapuches, p. 363. De esto informa también Ambrosio Benavides el 4 de junio de 1786. Escribe: "En el parlamento general de Lonquilmo tenido con los infieles de la frontera de este Reyno el año 1784 solicitaron los caciques e indios de las comarcas de la imperial y de Lolco que se les fundasen misiones en sus respectivos territorios para su instrucción en la fee católica y educación cristiana de sus hijos". Carta de Ambrosio Benavides al Virrey. AN, CMV. Vol. 4. Pieza 26. f. 47v.
} 
el transito a Valdivia"98. Parece clara, entonces, la aceptación que alcanzó la obra franciscana entre los indígenas fronterizos. En el Parlamento de Negrete de 1803, instancia a la que asistieron representantes de los cuatro vutanmapus, los caciques de las reducciones de Santa $\mathrm{Fe}$, Angol, Maquehuea, Lebcoyan y otras parcialidades interiores expresaron:

"la solicitud de su difunto Governador Levigueque, que hizo en el Parlamento General el año pasado de mil setecientos noventa y tres para que se les diese Micioneros de Propaganda en lugar del cura que les tienen puesto, como una necesidad suma espiritual; y mucho mas, por que hallandose los Butalmapus en la mejor dispocicion que han manifestado acerca de los padres, y ser aquel puesto de donde salian y se esparcian las miciones por la tierra, como en el recidia el superior de ellas, podrian con este paso verificar lo mismo para lo succesivo, por lo que lo repitieron a voz comun con el mayor empeño" 99 .

En el mismo parlamento, los caciques de todas las parcialidades llegaron al consenso de que el requerimiento de nuevos padres seráficos era uno los "medios de afirmar la tranquilidad y sosiego que les resulta, y tienen por experiencia" ${ }^{100}$. En consecuencia, el Colegio de Propaganda Fide de Chillán no quedó relegado al papel secundario que querían darle los funcionarios ilustrados. De igual manera, las declaraciones de los caciques dejan en claro que ocupó una posición especial dentro del imaginario indígena, granjeándose la aceptación de los mapuches, muy diferente de la conceptualización usualmente negativa que hacían del ejército o cualquier otra institución secular. Lo que es más, ni siquiera para la Corona era comparable a otro medio, ya que se valieron de la institución seráfica para pacificar, evangelizar y educar poblaciones asentadas en espacios geográficamente distantes como las tierras altas de los pehuenches o las planicies costeras de Arauco. Así las cosas, afirmar que el Colegio de Propaganda se articuló como uno de los instrumentos más efectivos en la frontera interna para generar, mantener y prolongar las relaciones pacíficas, tan necesarias para el orbe Borbón y su proyecto de reactivación periférica, no parece algo exagerado.

\section{El colegio de propaganda frente al enemigo extranjero}

Apenas iniciado el siglo XVIII llegó a manos del obispo de Santiago una cédula del rey Carlos III sobre un acontecimiento que despertó generalizadas alarmas ${ }^{101}$. Se trataba del lance escocés intentando penetrar en las fronteras hispanas de la región de El Darién, en el istmo de Panamá, con la intención de establecer una colonia. La nueva centuria estuvo demarcada por una intensa política defensiva orientada a resguardar los puntos más vulnerables del dominio hispano en

\footnotetext{
98 Ibídem.

99 Ibíd., p. 418.

100 Ibídem.

${ }^{101}$ Real cédula al obispo de Santiago. 27 de marzo de 1700. En Lizana. 1919. CAAS, Cedulario 1700-1720, tomo IV, p. 1.
} 
ultramar. Aunque la tentativa escocesa culminó en fracaso, para el rey de España no era una incógnita lo extremadamente expuestos que estaban los flancos más extremos y alejados de los territorios que señoreaba, especialmente a lo largo de sus dilatadas costas. El soberano católico destacó el peligro que representaba para el territorio y sobre todo para la "sagrada religión" cualquier incursión foránea, pues estaba en riesgo la "pureza" ${ }^{102}$ del cristianismo americano. Sin embargo, su deseo distaba de las posibilidades materiales y humanas del Imperio, pues el real erario estaba "apurado y exhausto" y se agotaba a causa de las guerras que se libraban en Europa ${ }^{103}$. América, de este modo, ocupaba un lugar clave en el juego estratégico internacional.

En 1718 el gobernador de Chile, Gabriel Cano de Aponte, concluyó que el reino se encontraba en estado lastimoso en cuanto a sus defensas, aconsejando el desembarco "de alguna infantería" para la protección de la costa ${ }^{104}$. A pocos meses de haber asumido las riendas de la gobernación lo que más lo sorprendió fue la facilidad con que las naves extranjeras recalaban en suelo americano. Esto se hizo particularmente evidente el 14 de mayo de 1741, cuando la fragata británica HMS Wager naufragó al sur del Golfo de Penas. La embarcación era parte de la escuadra de George Anson, quien desempeñó un rol preponderante durante las primeras operaciones inglesas en la Guerra del Asiento (1739-1748), enmarcada en las disputas territoriales y el contrabando inglés en América como consecuencia de las cláusulas impuestas a España en el Tratado de Utrecht $(1713)^{105}$. En palabras de la historiadora María Ximena Urbina, el interés inglés fue posicionarse en el Pacífico sur, tomando puertos y estableciendo alianzas con los indígenas ${ }^{106}$. Si, por un lado, la posibilidad de un alzamiento indígena fue una amenaza siempre latente, también pendía -cual espada de Damocles-el temor a una invasión extranjera. El miedo a una desafortunada confluencia de estos dos peligros fue constante durante el siglo XVIII ${ }^{107}$.

En la década de 1760 la actividad inglesa en las costas fue relativamente alta, dando cuenta de ello cuantiosas referencias en crónicas y comunicados depositados en los archivos institucionales. En 1767, un año después de iniciado el alzamiento indígena, el gobernador Antonio de Guill y Gonzaga recibió numerosos despachos alertando sobre la existencia de posibles asentamientos ingleses en el sur del reino. El riesgo se hizo más latente cuando comenzó a circular la noticia de que los intrusos habían logrado establecer nexos de

\footnotetext{
102 Ibídem.

103 Ibíd., p. 3.

${ }^{104}$ Carta de Cano de Aponte a Su Majestad. 20 de abril de 1718. AN, CMV. Vol. 4. Pieza 43. f. 91v.

105 Urbina, María. 2011. "La proyección colonial de Chile en la Patagonia Insular en el siglo XVIII", en Anuario de Estudios Americanos, Vol. 68, № 2, p. 604.

106 Ibídem.

107 León, Leonardo. 1994. “Los araucanos y la amenaza de ultramar, 1750-1807”, en Revista de Indias, Vol. 54, № 201, Madrid, pp. 313-354.
} 
intercambio con los indígenas locales ${ }^{108}$. Aunque poco tiempo después el peligro se alejó del reino, la amenaza de una nueva arremetida permaneció latente dentro de los límites del dominio colonial pues los ingleses asentaron una base de operaciones en las islas Falkland ${ }^{109}$. En carta de Manuel de Amat, virrey del Perú, al ministro de Indias, relató su parecer en lo tocante a las embarcaciones inglesas:

“(...) es muy verosímil que de orden de almirantazgo de Inglaterra con permiso de aquel ministerio, se haya remitido las embarcaciones que se refieren no con el fin de las internaciones hasta el Paraguay, y Patagones, ni hacer otros progresos, que suenen á conquista; sino con el verdadero deseo de instruirse y demarcar el sitio mas comodo para una colonia en que observan las ventajas que se han propuesto asi en tiempo de Paz, como en el de guerra. Con esta idea es natural que aya conversado con uno si otro de los salvajes que avitan aquellos yermos, que ayan fondeado los puertos discurrido por las tierras y practicado cuantas operaciones conducen a dar el golpe con acierto" ${ }^{110}$.

La posibilidad de una colonia no era lejana, los escoceses lo habían intentado en El Darién y el avance inglés fue sostenido y permanente en el norte del continente. Lo que despertó el mayor temor fue la siempre amenazante posibilidad de diálogo y entendimiento de los protestantes con "los salvajes que avitan aquellos yermos". El 31 de enero de 1769 una carta de Francisco Bucarelli, gobernador de la provincia de Buenos Aires, informaba sobre asentamientos ingleses en las inmediaciones de Chiloé. De esta manera, el 25 de julio del mismo año la Corona tomó cartas en el asunto, proponiendo al gobernador de Buenos Aires y al presidente de Chile que comprometieran recursos y hombres en contener las operaciones inglesas promoviendo "con el mayor esfuerzo las misiones de las tierras Magallánica y del Fuego a costa del caudal de temporalidades ocupadas a los Regulares de la Compañía (...), por lo mucho que importa precaver con tiempo que los ingleses no atraigan con su comercio aquellos indios, como se puede tener si no se acude con actividad al remedio"111.

Más explícita es la consulta del Consejo de Indias de 28 de julio de 1769, en la cual tuvo injerencia Pedro Rodríguez de Campomanes; en esta se manda:

"evitar que los ingleses atraigan con su comercio los indios, como es de temer sino se acude con actividad al remedio, ha acordado se comunique la orden al expresado D[on] Francisco Bucareli, y al presidente de la Audiencia Governadora de Chile para que de acuerdo y con el mayor esfuerzo promueva por ahora las misiones en las tierras Magallanicas y del Fuego á

\footnotetext{
108 Noticias sobre el establecimiento y comercio de ingleses. 13 de noviembre de 1767. AN, CMV. Vol. 22. Pieza 12. f. 244.

109 Ibíd., f. 247.

110 Ibíd., f. 256v.

111 Ibíd., f. 283v.
} 
costa del caudal de temporalidades ocupadas a los Regulares de la Compañía a fin de evitar otro nuevo establecimiento en alguno de aquellos parages, y avisen incesantemente de quanto se vaya adelantando"112.

De esta forma a las misiones franciscanas, que en ese momento eran la única alternativa apostólica luego de la expulsión de la Compañía de Jesús, se les asignó una nueva tarea. El impulso de la Corona por implementar una política misional para frenar los lances extranjeros había otorgado una nueva dimensión a la misión del Colegio de Propaganda Fide. Por lo tanto, tras el extrañamiento de los jesuitas el Colegio tuvo una participación directa en la contención del peligro externo, por lo menos a nivel de gobernanza ${ }^{113}$. Sin embargo, a poco andar se vio que las intenciones iban muy por delante de las posibilidades que brindaban los medios. En efecto, en una comunicación de Francisco Javier Morales al ministro de Indias de 15 de marzo de 1770, se dio aviso de que las misiones nunca se concretaron por la "total falta de medios para su consecusión", medios que el virrey había prometido. Las razones que Morales comunica son dos: que, según dice, el "levantamiento general de indios de esta Frontera ha consumido entre todos los ramos de Real hacienda el de temporalidades de Jesuitas expatriados de este Reyno sin que se haya suplido este defecto de las Cajas Reales de Lima" ${ }^{114}$; y la imposibilidad de designar misioneros por la escasez de padres en el obispado de Concepción. Los dos temores, el foráneo y el interno, habían confluido en una misma preocupación poniendo al reino de Chile y a la Corona en jaque. De esta manera, los franciscanos se vieron en la obligación de tener que reasumir un papel que los jesuitas habían desempeñado activamente en el entramado fronterizo, cuando menos hasta la rebelión de 1723: asistir y asesorar con su experiencia y consejo a los parlamentos hispano-mapuches, lo que da cuenta de la capacidad franciscana de generar y mantener las relaciones de entendimiento interétnico en la frontera interna y, por consiguiente, que las misiones seráficas tuvieron una participación indirecta en el control del enemigo externo. Mantener la paz con los mapuches era esencial para evitar que entraran en contacto con las potencias extranjeras, por lo que cualquier impulso para generar vínculos interétnicos era aprovechado por el Estado borbón. Así, en la década de 1770 Pedro Ángel de Espiñeira preconizó las alternativas pacíficas por sobre las opciones de guerra de exterminio, apoyando los pactos de paz ${ }^{115}$. Por lo tanto, los parlamentos a fines de siglo fueron el resultado de la complementariedad entre el accionar de Espiñeira y los seráficos, y del anhelo

\footnotetext{
112 Ibíd., f. 285v. La cursiva es nuestra.

113 La política imperial se manifestó bajo una lógica similar en la Alta California, donde el visitador general José de Gálvez gestionó el establecimiento de sacerdotes provenientes del Colegio de Propaganda Fide de San Fernando de México para controlar a los nativos locales e impedir, de esta manera, la expansión de potencias europeas rivales en la costa septentrional del Pacífico. Véase Weber. 2005. Bárbaros, p. 122.

${ }^{114}$ Noticias sobre el establecimiento y comercio de ingleses. 13 de noviembre de 1767. AN, CMV. Vol. 22. Pieza 12. f. $288 \mathrm{v}$.

115 Pinto. 1986. "Estudio Preliminar", p. 32.
} 
de estabilidad de los representantes de la Corona. En consecuencia, respecto a su responsabilidad de mantener la paz, los franciscanos indirectamente se hicieron cargo del peligro externo lo que se aprecia claramente en el Parlamento de Negrete de 1771, en el cual se llegó al acuerdo con los naturales de:

"mantenerse en todas ocaciones Amigos de nuestros Amigos, y Enemigos de nuestros Enemigos. Sin que a estos con ningun Titulo o pretexto ayuden, fomenten, ni den malos consejos; Y por el contrario seran obligados a tomar las Armas contra ellos, castigarlos, y destruirlos para que se reconosca la buena amistad, y correspondencia que guardan a los Españoles. Y principalmente observaran esta buena fee contra Enemigos de extraña Corona, no permitiendo salten de sus Naos a nuestras Costas, ni que permuten Bastimentos algunos: por que antes son obligados a retirar sus Ganados Dies leguas Tierra dentro para que no se aprovechen de ellos ny sirvan de alisiente a su demora. Daran prontos avisos al Maestre de Campo General, y al Superior Gobierno de su arrivada, y en consorcio de los Españoles se esforzaran a desalojarlos de toda la jurisdicion del Reyno"116.

En el Parlamento de Tapihue de 1774 se logró el mismo acuerdo. Con todo, frente al enemigo extranjero, la Corona instó a la participación de los misioneros de Chillán, los cuales, al ser un instrumento generador de relaciones pacíficas, ayudaron a contener el peligro en los territorios de ultra Biobío, limitando considerablemente la posibilidad de una alianza o concatenación entre los dos frentes de batalla, el doméstico y el foráneo.

\section{Conclusión}

Después de 1726 la Corona renunció a la conquista militar de la Araucanía, incentivando el intercambio comercial. Esta libertad vino a acrecentar el territorio dominado por indígenas libres, que para mediados del siglo XVIII representaba más de la mitad del espacio hispanoamericano ${ }^{117}$. Desde la perspectiva de los administradores, los indios libres ocupaban las fronteras del imperio; desde la visión de los indígenas no sometidos, eran los españoles los que controlaban los límites de sus tierras ${ }^{118}$. Además, el siglo XVIII es fundamental en el desarrollo de las potencias enemigas de España, que, sedientas de arrebatar un pedazo del gran botín americano, acecharon las costas del Nuevo Mundo en todo momento de la centuria. Por ende, el siglo XVIII es clave en cuanto a las relaciones fronterizas en Chile, ya que los funcionarios borbónicos buscaron con celo ejemplar la lealtad de los indígenas no sometidos. Además, las presiones del conflicto internacional forzaron al aparato estatal a volcarse al

\footnotetext{
116 Zavala. 2015. Los Parlamentos Hispano-Mapuches, p. 283.

117 Weber, David. 1998. "Borbones y bárbaros. Centro y periferia en la reformulación de la política de España hacia los indígenas no sometidos", en Anuario IEHS, №13, Tandil, p. 147.

118 Ibídem.
} 
desarrollo y reactivación económica, urgiendo con fuerza algún tipo de control en pro de la estabilización de las relaciones con los indios que ocupaban las zonas fronterizas ${ }^{119}$ y la protección de las costas del enemigo foráneo.

Con todo, los misioneros del Colegio de Propaganda Fide de Chillán representaron una alternativa renovadora de la fuerza evangelizadora, en tanto los métodos ignacianos se encontraban desprestigiados luego de las rebeliones de 1723 y 1766. Después de 1767, los grandes peligros que acecharon el territorio meridional del imperio hicieron que la Corona recurriese a la única institución misional del momento, en detrimento de los proyectos de hombres distinguidos e ilustrados, apelando a la utilidad que el trabajo de los seráficos tendría para el orden civil. Y si bien no lograron la evangelización de los territorios allende el Biobío, el poder Borbón los colocó en tareas diversas y dinámicas, adquiriendo una doble naturaleza, en tanto instrumento dialogador, esencial sostén (junto al parlamento) de la paz y el comercio, lo que indirectamente redujo el riesgo de las incursiones extranjeras; y como institución apostólica entre los naturales, propagando la fe y haciéndose cargo de la obligación histórica de la Corona, pretexto de la conquista, que era la de evangelizar a los infieles en el Nuevo Mundo. Por lo tanto, el Colegio fue clave en la nueva política de los regentes ilustrados, siendo la punta de lanza contra el indio alzado y contra el enemigo inglés.

En otro sentido, los mismos misioneros seráficos se enmarcaron dentro una lucha contra la infidelidad al tiempo que criticaron los medios de pacificación fronteriza usados hasta ese entonces, seculares o religiosos; se desenvolvieron, con celo ejemplar, entre los naturales siguiendo un estricto método con fases de desarrollo.

Con todas estas variables en juego, es difícil aceptar entonces las opiniones de diversos autores, coloniales y actuales, sobre el fracaso misional del Colegio de Propaganda Fide. Porque tal vez no logró la derrota de la infidelidad, pero el rol que tuvo para el Estado y para los naturales como intermediario, conteniendo el peligro extranjero o misionando en la cordillera, lo aleja, determinantemente, del fracaso meramente misional.

\section{Fuentes y bibliografía}

\section{Fuentes}

AN, CMV: $\quad$ Archivo Nacional de Santiago, Fondo Carlos Morla Vicuña

AN, FA:

Archivo Nacional de Santiago, Fondo Antiguo

AFCC:

Archivo Franciscano del Colegio de Chillán

BM:

Biblioteca Nacional, Fondo José Toribio Medina

119 Ibíd., pp. 147-151. 
Amat, Manuel de. 1769. Informe del Virrey Manuel de Amat en que critica las medidas de Guill y Gonzaga, 1769. BM, Ms. Tomo 292. Documento 8845. fs. 291-310.

Arriaga, Julian de. 1767. Noticias sobre el establecimiento y comercio de ingleses por Fray Julian de Arriaga, Secretario de Indias, 13 de noviembre de 1767. AN, CMV. Vol. 22. Pieza 12. fs. 244-245v.

Benavides, Ambrosio de. 1786. Carta de Ambrosio Benavides al Virrey, 1786. AN, CMV. Vol. 4. Pieza 26. fs. $47 v-49 v$.

Cano de Aponte, Gabriel. 1718. Carta de Cano de Aponte a Su Majestad, 20 de abril de 1718. AN, CMV. Vol. 4. Pieza 43. fs. 89v-91v.

Gondar, José. 1762. Copia del informe que hizo al señor presidente del Reino de Chile José Gondar, 28 de septiembre de 1762. AFCC. Vol. 1. Doc. 79. fs. 341-354.

Morales, Francisco Javier de. 1771. Noticias sobre el establecimiento y comercio de ingleses de Francisco Javier Morales, Ministro de Indias, 11 de enero de 1771. AN, CMV. Vol. 22. Pieza 18, fs. 287-288v.

Puebla González, Francisco de la. 1700. Carta del Obispo de Santiago a Su Majestad, 1700. AN, CMV. Vol. 3. Pieza 3. fs. 3-5v.

Recabarren, Martín de. 1739. Informe de Martín de Recabarren al Rey, sobre los medios de reducir a los indios de Chile y conservar la quietud del reino, 1739. AN, FA. Vol. 32. Pieza 3. fs. 22-28.

Salamanca, Manuel de. 1736. Carta de Manuel de Salamanca a S.M., 26 de septiembre de 1736. AN, CMV. Vol. 5. Pieza 85. fs. 316-319.

\section{Libros}

Ares, Berta y Gruzinski, Serge (coords.). 1997. Entre dos mundos. Fronteras culturales y agentes mediadores, Sevilla, Consejo Superior de Investigaciones Científicas, 1997.

Barros Arana, Diego. 1886. Historia Jeneral de Chile, tomo VI, Santiago, Rafael Jover.

Boccara, Guillaume. 2007. Los vencedores. Historia del pueblo mapuche en la Época Colonial, Santiago, IIAM.

Burke, Peter. 2010. Hibridismo cultural, Madrid, Akal ediciones.

Casanova, Holdenis. 1987. Las rebeliones araucanas del siglo XVIII. Mito y realidad, Temuco, Ediciones Universidad de La Frontera.

Elliott, John. 2011. Imperios del Mundo Atlántico. España y Gran Bretaña en América (1492-1830), Madrid, Taurus Ediciones.

Foerster, Rolf. 1996. Jesuitas y Mapuches, 1593-1767, Santiago, Editorial Universitaria.

Guarda, Gabriel. 1990. Flandes Indiano. Las fortificaciones del Reino de Chile, 1541-1826, Santiago, Ediciones de la Universidad Católica.

Guarda, Gabriel. 2016. La Edad Media en Chile. Historia de la Iglesia: desde la fundación de Santiago a la incorporación de Chiloé, 1541-1826, Santiago, Ediciones UC.

Lagos, Roberto. 1908. Historia de las misiones del Colegio de Chillán, Vol. 1, Barcelona, Herederos de Juan Gili Editores.

León, Leonardo. 1990. Maloqueros y conchavadores en Araucanía y las Pampas, 1700-1800, Temuco, Ediciones Universidad de la Frontera.

Martínez, Enrique y De Pazzis Pi Corrales, Magdalena (eds.). 2008. Ilustración, ciencia y técnica en el siglo XVIII español, Valencia, PUV.

Metcalf, Alida. 2005. Go-betweens and the colonization of Brazil, 1500-1600, Austin, University of Texas Press. 
Pereira Contardo, Karin. 2002. El Real Colegio de Naturales, Santiago, Publicaciones del Archivo Franciscano (PAF), № 73.

Rex Galindo, David, 2018. To sin no more: Franciscans and conversion in the Hispanic world, 1683-1830, Stanford, Stanford University Press/The Academy of American Franciscan History.

Stewart Stokes, Hamish. 2000. Del Mar del Norte al Mar del Sur: navegantes británicos y holandeses en el Pacífico suroriental, 1570-1807, Valparaíso, Editorial Puntángeles.

Wallerstein, Immanuel. 2011. The modern world-system: mercantilism and the consolidation of the European world-economy, 1600-1750, Berkeley, University of California Press.

Weber, David. 2005. Bárbaros: Spaniards and their savages in the Age of Enlightenment, New Haven, Yale University Press.

Zavala, José. 2008. Los mapuches del siglo XVIII. Dinámica interétnica y estrategias de resistencia, Santiago, Editorial Universidad Bolivariana.

\section{Capítulos de libro}

Altube, María Inés. 1999. "Mujeres en 'tierra adentro'. Las cautivas en las sociedades indígenas de la región pampeana y norpatagónica (siglos XVIII y XIX)", en Villar, Daniel, Di Liscia, María y Caviglia, María Jorgelina (eds.). Historia y género: seis estudios sobre la condición femenina, Buenos Aires, Editorial Biblos, pp. 89-120.

Casanova, Holdenis. 1988. "Presencia Franciscana en la Araucanía. Las misiones del Colegio de Propaganda Fide de Chillán (1756-1818)", en Pinto, Jorge, Casanova, Holdenis, Uribe, Sergio, y Matthei, Mauro (eds.). Misioneros en la Araucanía, 1600-1900, Temuco, Ediciones Universidad de La Frontera, pp. 121-197.

Escribano R., Rodrigo. 2015. "Frailes y cautivas. Un caso de negociación interétnica en la frontera hispano-mapuche (1752-1760)", en Cañedo-Argüelles, Teresa (coord.). América. Cruce de miradas, Vol. 2, Alcalá de Henares, Universidad de Alcalá/Asociación Española de Americanistas, pp. 551-575.

Gómez Canedo, Lino. 1976. "Evangelización y política indigenista. Ideas y actitudes franciscanas en el siglo XVI", en Seminario de Historia de América de la Universidad de Valladolid (ed.). Estudios sobre política indigenista española en América, Vol. II, Valladolid, Universidad de Valladolid, pp. 21-46.

Gómez Canedo, Lino. 1988. "Aspectos característicos de la acción franciscana en América”, en Actas del Il Congreso Internacional sobre los franciscanos en el Nuevo Mundo, Madrid, Editorial Deimos, pp. 441-472.

Inostroza, Iván. 2014. "El circuito colonial hispano-mapuche, 1660-1710", en Pinto, Jorge, e Inostroza, Iván. Expansión capitalista y economía mapuche: 1680-1930 y Tres Razas, 1887, Temuco, Ediciones Universidad de la Frontera, pp. 21-41.

Pereira Contardo, Karin. 2005. "Del Colegio al Seminario de Naturales: los franciscanos y la educación indígena en Chile, 1786-1811", en Millar Carvacho, René y Aránguiz Donoso, Horacio (eds.). Los franciscanos en Chile: una historia de 450 años, Santiago, Academia Chilena de la Historia, pp. 171186.

Pinto, Jorge. 1986. "Estudio Preliminar", en Sala, Joseph de la. Visita General de la Concepción y su Obispado por Fray Pedro Ángel de Espiñeyra, Chillán, Ediciones del Instituto Profesional de Chillán, pp. 3-49.

Pinto, Jorge. 1988. “Frontera, misiones y misioneros en Chile y Araucanía (1600-1900)”, en Pinto, Jorge, Casanova, Holdenis, Uribe, Sergio, y Matthei, Mauro (eds.). Misioneros en la Araucanía, 1600-1900. Un capítulo de historia fronteriza en Chile, Temuco, Ediciones Universidad de La Frontera, pp. 17-119. 
Pizzorusso, Giovanni. 2016. "The Congregation de Propaganda Fide, the Holy See and the native peoples of North America (17 $7^{\text {th }}-19^{\text {th }}$ centuries)", en Cummings, Kathleen y Sanfilippo, Matteo (eds.). Holy See's archives as sources for American history, Vitterbo, Sette Città, pp. 13-53.

Viñuela Pérez, Rebeca. 2015. "Los franciscanos del Colegio de Propaganda Fide de San Idelfonso de Chillán como mediadores políticos en la frontera araucana del siglo XVIII", en Cañedo-Argüelles, Teresa (coord.). América. Cruce de miradas, Vol. 2, Alcalá de Henares, Universidad de Alcalá/Asociación Española de Americanistas, pp. 577-602.

\section{Artículos}

Areces, Nidia. 1999. "Regiones y fronteras. Apuntes desde la historia”, en Andes, № 10, Salta, pp. 19-31. Disponible en: http://www.icsoh.unsa.edu.ar/numeros-andes/andes-1999-10/.

Chuecas S., Ignacio. 2016. “India salvaje, letrada y litigante. Una mujer indígena de la 'tierra adentro' ante la justicia colonial. Chile, 1760", en Revista Historia y Justicia, $\mathrm{N}^{\circ}$ 6, Santiago, pp. 258-273. https://doi.org/10.4000/rhj.629

Enrique, Laura. 2012. “Aportes de los 'intermediarios culturales' en la conformación de los paisajes fronterizos del norte de la Patagonia a fines del siglo XVIII", en Memoria Americana, Vol. 20, № 2, Buenos Aires, pp. 245-271. Disponible en: http://www.scielo.org.ar/scielo.php?script=sci_arttext\&pid=S1851-37512012000200004\&lang=es.

Gándara, Natalia. 2016. "Representaciones de un territorio. La frontera mapuche en los proyectos ilustrados del Reino de Chile en la segunda mitad del siglo XVIII", en Historia Crítica, $\mathrm{N}^{\circ}$ 59, Bogotá, pp. 61-80. http://dx.doi.org/10.7440/histcrit59.2016.04

Leal, Cristián y Quitral, Andrés. 2017. “Evangelización y occidentalización en la frontera sur del Reino de Chile. Los franciscanos del Colegio de Misiones de Chillán, s. XVIII", en Historia y Memoria, № 15, Boyacá, pp. 139-168. https://doi.org/10.19053/20275137.n15.2017.5588.

León, Leonardo. 1994. "Los araucanos y la amenaza de ultramar, 1750-1807”, en Revista de Indias, Vol. 54, № 201, Madrid, pp. 313-354.

León, Leonardo. 2001. "Que la dicha herida se la dio de buena sin que interviniese traición alguna...: El ordenamiento del espacio fronterizo mapuche, 1726-1760", en Revista de Historia Social y de las Mentalidades, № 5, Santiago, pp. 129-165. Disponible en: http://www.revistas.usach.cl/ojs/index.php/historiasocial/article/view/310/305.

Mantecón, Tomás y Truchuelo, Susana. 2016. "La(s) frontera(s) exteriores e interiores de la Monarquía Hispánica: perspectivas historiográficas", en Historia Crítica, № 59, Bogotá, pp. 19-39. http://dx.doi.org/10.7440/histcrit59.2016.02.

Nicoletti, María. 2002. "Jesuitas y Franciscanos en las misiones de Norpatagonia. Coincidencias y controversias en su discurso teológico", en Anuario de la Historia de la Iglesia, Vol. 11, Navarra, pp. 215-237. Disponible en: http://hdl.handle.net/11336/82679.

Osorio, Jaime. 2015. "El sistema-mundo de Wallerstein y su transformación. Una lectura crítica", en Argumentos, Año 28, $\mathrm{N}^{\circ}$ 77, México D.F., pp. 131-154. Disponible en: http://www.scielo.org.mx/scielo.php?script=sci_arttext\&pid=S0187-57952015000100007.

Pinto, Jorge. 1991-92. "Etnocentrismo y etnocidio. Franciscanos y jesuitas en la Araucanía, 1600-1900", en Nütram, Año VII, N²4, Santiago, pp. 3-23.

Poblete S., María. 2008. "Mapuche-huilliches e hispano-criollos en Valdivia. Cartas de petición y procesos de articulación en el periodo colonial tardío", en Cultura, Hombre, Sociedad, Vol. 15, N², Temuco, pp. 49-60. http://dx.doi.org/10.7770/cuhso-V15N2-art269.

Poblete S., María. 2009. “Prácticas educativas misionales franciscanas, creación de escuelas en territorio mapuche y significado de la educación para los mapuche-huilliche del siglo XVIII y XIX", en Espacio 
Regional, Vol. 2, $\quad \mathrm{N}^{\circ}$ 6, Osorno, pp. 23-33. Disponible en: https://dialnet.unirioja.es/servlet/articulo?codigo=3676337.

Puig-Samper, Miguel. 2011. "Las expediciones científicas españolas en el siglo XVIII", en Canelobre, № 57, Alicante, pp. 21-41.

Quijada, Mónica. 2002. "Repensando la frontera sur argentina: concepto, contenido, continuidades y discontinuidades de una realidad espacial y étnica (siglos XVIII-XIX)", en Revista de Indias, Vol. LXII, № 224, Madrid, pp. 103-142. https://doi.org/10.3989/revindias.2002.i224.461.

Ratto, Silvia. 2005. "Caciques, autoridades fronterizas y lenguaraces: intermediarios culturales e interlocutores válidos en Buenos Aires (primera mitad del siglo XIX)", en Mundo Agrario. Revista de estudios rurales, Vol. 5, № 10, La Plata. Disponible en: https://www.redalyc.org/articulo.oa?id=84501008.

Rex Galindo, David. 2014. "'Primero hombres, luego cristianos': un análisis sobre la conversión forzosa en la frontera de Texas", en Colonial Latin American Historical Review, (second series), Vol. 2, N 3, Albuquerque, pp. 405-432. https://digitalrepository.unm.edu/clahr/vol19/iss3/6/.

Rodríguez, Humberto. 1999. "Manuel de Amat y Junyent y la Navona de Lima: un ejemplo de diseño urbano barroco del siglo XVIII en el virreinato de Perú", en Anales del Instituto de Investigaciones Estéticas, Vol. XXI, № 74-75, México $\quad$ D.F., pp. 147-176. https://www.redalyc.org/articulo.oa?id=36907408.

Urbina Carrasco, María. 2011. "La proyección colonial de Chile en la Patagonia Insular en el siglo XVIII", en Anuario de Estudios Americanos, Vol. 68, № 2, Sevilla, pp. 599-622. https://doi.org/10.3989/aeamer.2011.v68.i2.551

Weber, David. 1998. "Borbones y bárbaros. Centro y periferia en la reformulación de la política de España hacia los indígenas no sometidos", en Anuario IEHS, № 13, Tandil, pp. 147-171. Disponible en: http://anuarioiehs.unicen.edu.ar/1998.html.

Wilde, Guillermo. 1999. “¿Segregación o asimilación? La política indiana en América meridional a fines del periodo colonial", en Revista de Indias, Vol. LIX, N²17, Madrid, pp. 619-644. Disponible en: http://revistadeindias.revistas.csic.es/index.php/revistadeindias/article/view/830/899.

\section{Fuentes editadas}

Alday, Manuel de. 1919 (1755). "Carta del Obispo electo D. Manuel de Alday al rey, de 18 de febrero de 1755", en Lizana, Elías (ed.), Colección de documentos históricos del Arzobispado de Santiago. Cartas de los obispos al rey, 1564-1814, tomo I, Santiago, Imprenta Laguna \& Co., pp. 505-508.

Amat y Junient, Manuel de. 1927 (¿1760?). "Historia Geographica e Hidrographica con derrotero general correlativo al plan de el Reyno de Chile que remite a nuestro Monarca el señor don Carlos III su gobernador y capitán general don Manuel de Amat y Junient; ¿1760?”, en Revista Chilena de Historia y Geografía, Tomo LII, N 56, pp. 360-401.

Ascasubi, Miguel de, OFM. 2007 (1789). Informe cronológico de las misiones del Reino de Chile, hasta 1789. Santiago, PAF, № 49.

Carlos II, rey de España. 1921 (1700). “Real cédula al obispo de Santiago, de 27 de marzo de 1700”, en Lizana, Elías (ed.), Colección de documentos históricos del Arzobispado de Santiago. Cedulario, tomo IV, Santiago, Imprenta Laguna \& Co., pp. 1-5.

Carrasco, Bernardo. 1919 (1695). "Carta de Fr. Bernardo Carrasco al Rey, de 12 de septiembre de 1695", en Lizana, Elías (ed.), Colección de documentos históricos del Arzobispado de Santiago. Cartas de los obispos al rey, 1564-1814, tomo I, Santiago, Imprenta Laguna \& Co., pp. 406-418.

Carvallo y Goyeneche, Vicente. 1875 (1796). Descripción Histórico-Jeográfica del Reino de Chile, tomo II, Colección de Historiadores de Chile, vol. IX, Santiago, Imprenta de "La Estrella de Chile". 
Gondar, José. 1994 (1758). "Carta del P. José Gondar al P. Fray Antonio Herosa, de 4 de mayo de 1758", en López, Atanasio, Cartas de los misioneros del Colegio de Chillán, Madrid, Archivo Ibero-Americano, pp. 165-176.

Iturriaga, Rigoberto (transcripción y notas). 1992 (1775). Reglamento de misiones del Colegio de Chillán, Santiago, Publicaciones del Archivo Franciscano, № 21.

Ojeda, Juan de. 1898 (1803). "Informe descriptivo de la frontera de la Concepción de Chile, por el coronel don Juan de Ojeda, 1803”, en Anrique, Nicolás, Biblioteca Jeográfico-Hidrográfica de Chile (segunda serie), Santiago, Imprenta Elzeviriana, pp. 219-292.

Pozo y Silva, Alonso del. 1919 (1730). "Carta de D. Alonso del Pozo y Silva al Rey, de 17 de marzo de 1730", en Lizana, Elías (ed.), Colección de documentos históricos del Arzobispado de Santiago. Cartas de los obispos al rey, 1564-1814, tomo I, Santiago, Imprenta Laguna \& Co., pp. 482-485.

Rodríguez Tena, Fernando. 2003 (1780). El Colegio Apostólico de Chillán, Santiago, PAF, № 80, 2003.

Salas, José Perfecto de. 1963 (1752). "Informe dirigido al rey sobre el reino de Chile, 1752", en Donoso, Ricardo, Un letrado del siglo XVIII, el doctor José Perfecto de Salas, vol. I, Buenos Aires, Universidad de Buenos Aires, Facultad de Filosofía y Letras, pp. 103-133.

Scío de San Miguel, Phelipe. 1793. La Biblia vulgata latina traducida en español, y anotada conforme al sentido de los Santos Padres y expositores Catholicos, tomo VII del Antiguo Testamento: Las phrofecías de Jeremías y sus threnos, las de Baruch, de Ezequiel y de Daniel. Valencia, Oficina de Joseph y Thomas de Orga.

Zavala, José (ed.). 2015. Los Parlamentos Hispano-Mapuches, 1593-1803: textos fundamentales. Temuco, Ediciones Universidad Católica de Temuco. 